\title{
CONTEXTO PALEODEPOSICIONAL DE UM SISTEMA EÓLICO CAMBRIANO: FORMAÇÕES PEDRA PINTADA E PEDRA DAS TORRINHAS (BACIA DO CAMAQUÃ, BRASIL)
}

PALAEODEPOSITIONAL CONTEXT OF A CAMBRIAN AEOLIAN SYSTEM: PEDRA PINTADA AND PEDRA DAS TORRINHAS FORMATIONS (CAMAQUÃ BASIN, BRAZIL)

\author{
CARLOS HENRIQUE GOMES TABARELLI ${ }^{1}$, ÁQUILA FERREIRA MESQUITA ${ }^{2}$ \& \\ JULIANA PERTILLE DA SILVA ${ }^{1}$ \\ 1 Universidade Federal de Pelotas - UFPel, Campus Porto. Rua Gomes Carneiro, 01 - Balsa, Pelotas - RS. E-mail: ccarlostaba- \\ relli@gmail.com; juliana.pertill@gmail.com \\ 2 Universidade Estadual de Campinas - Unicamp, Cidade Universitária Zeferino Vaz. Rua Carlos Gomes, 250 - Barão Geraldo, Campi- \\ nas - SP. E-mail: aquila.fmesquita@gmail.com
}

\begin{abstract}
Resumo A ausência de cobertura vegetal nas primeiras superfícies continentais proporcionou um amplo desenvolvimento de sistemas eólicos. Esses sistemas se desenvolveram com dinâmicas distintas de seus análogos modernos, principalmente porque a vegetação influencia diretamente o estilo de construção e acumulação eólica. A presente pesquisa teve como objetivo investigar uma sucessão sedimentar entre as Formações Pedra Pintada e Pedra das Torrinhas, de modo a compreender a interação entre sistemas eólicos e não-eólicos na margem de um rifte cambriano. O trabalho também propõe um modelo paleoambiental mais refinado para a sucessão estudada. A análise de fácies permitiu o reconhecimento de quatro ambientes deposicionais: dunas eólicas, interdunas secas, lençol de areia e fluxos de detritos. Esses sistemas coexistiram no tempo e se distribuíam em função da proximidade com as áreas fontes e das variações do lençol freático. Nas porções próximas à margem do rifte, lençóis de areia foram formados devido ao retrabalho dos depósitos de fluxos de detritos pela deflação do vento. Por outro lado, os campos de dunas desenvolveram-se potencialmente nas áreas mais internas da bacia. A influência da tectônica e/ou de eventos pluviométricos provavelmente controlou a contração e expansão desses sistemas temporalmente. Os dados coletados e as discussões deste trabalho permitiram que as seguintes considerações fossem feitas: (i) variações do lençol freático controlaram a umidade no sistema e a distribuição das áreas de sedimentação eólica; (ii) a ação constante do vento produziu uma seleção e reciclagem ininterrupta dos depósitos aluviais, abastecendo os sistemas eólicos; (iii) a ausência de vegetação proporcionou o melhor desenvolvimento dos fluxos gravitacionais na margem do rifte; (iv) o alto suprimento sedimentar na Terra pré-vegetação produziu uma deposição eólica constante, proporcionado o desenvolvimento simultâneo de sistemas não-eólicos e eólicos em pequena escala.
\end{abstract}

Palavras-chave: dunas eólicas; lençóis de areia; Grupo Guaritas; Bacia do Camaquã

\begin{abstract}
The absence of vegetation cover on the early continental surfaces provided the wide development of aeolian systems. These systems had a distinctive dynamic in relation to their modern analogues, mainly because the vegetation directly influences the style of aeolian construction and accumulation. The present research aimed to investigate a sedimentary succession between the Pedra Pintada and Pedra das Torrinhas formations, to understand the interplay between aeolian and non-aeolian systems in a Cambrian rift margin. The work also proposes a detailed palaeoenvironmental model based on the studied succession. The facies analysis allowed the recognition of four depositional environments: aeolian dunes, dry interdunes, sand sheet, and debris flows. They were coeval and distributed from the proximity to source areas of sediments and the variations of the water table. In the portions close to the rift margin, sand sheets formed due to the reworking of debris-flow deposits by wind deflation. Conversely, the dune fields concentrated in the distal areas of the basin. The influence of the tectonics and/or intense rainfall events probably controlled the contraction and expansion of these systems over time. The data collected and the discussions of this work allowed the following considerations to be made: (i) variations of the water table controlled the distribution of wetness and areas of aeolian sedimentation into the system.; (ii) the constant wind action produced an uninterrupted selection and recycling of alluvial deposits, supplying the aeolian systems; (iii) the absence of vegetation provided the best development of gravitational flows at the rift margin; (iv) the high sedimentary supply in the pre-vegetation landmasses produced a constant aeolian deposition, allowing the coeval development of non-aeolian and aeolian systems on a small scale.
\end{abstract}

Keywords: eolian dunes; sand sheets; Guaritas Group; Camaquã Basin 


\section{INTRODUÇÃO}

Os sistemas deposicionais que dominaram a paisagem continental anterior à evolução das primeiras plantas terrestres (Pré-Devoniano) demonstravam diferenças quanto à sua dinâmica sedimentar em relação aos seus correlatos modernos (Eriksson et al., 2005; Bose et al., 2012). A ausência de cobertura vegetal proporcionou elevadas taxas de erosão das superfícies continentais que, consequentemente, produziu um elevado suprimento de sedimentos para o transporte eólico e a maior intensidade dos processos sedimentares (Eriksson \& Simpson, 1998; Bose et al., 2012; Mesquita et al., 2021). Essas condições paleoambientais sugerem que os sistemas eólicos foram amplamente distribuídos na Terra pré-vegetação (Eriksson \& Simpson, 1988; Rodríguez-López et al., 2014). Em contraste, os sistemas eólicos atuais cobrem somente $20 \%$ das regiões continentais, principalmente as concentradas em zonas áridas/semiáridas da Terra (Mountney, 2006a; Al-Masrahy \& Mountney, 2013). Logo, a diferente participação do vento no transporte e deposição de sedimentos em ambientes deposicionais antigos e modernos foi progressivamente afetado pelo surgimento dos primeiros organismos vegetais (Rodríguez-López et al., 2014).

A sedimentação eólica atual, no interior dos continentes, ocorre preferencialmente em climas de baixas precipitação e que resultam em um substrato seco e com uma restrita cobertura vegetal, promovendo uma alta disponibilidade de sedimentos para a construção de dunas eólicas (Mountney, 2006a; Tsoar \& Pye, 2009). Por outro lado, as altas taxas de erosão continental e de suprimento sedimentar na Terra prévegetação produziram sistemas eólicos mais complexos (Rodríguez-López et al., 2014; Mesquita et al., 2021) e nos mais variados tipos climáticos e contextos tectônicos (e.g.,
Ross, 1983; Clemmensen, 1988; Deynoux et al., 1989; Biwas, 2005; Bállico et al., 2017; Lebeau \& lelpi, 2017; Basilici et al., 2021).

A Formação Pedra Pintada, Bacia do Camaquã (RS), é uma unidade cambriana originada pela deposição de sistemas eólicos úmidos e secos (Paim \& Scherer, 2003; Paim \& Scherer, 2007). Essa sucessão apresenta excelentes exposições verticais e horizontais dos depósitos, onde é possível realizar estudos sedimentológicos detalhados que possibilitam compreender a natureza e a dinâmica eólica em um contexto pré-vegetação. Apesar das diversas reconstruções paleoambientais para esse campo de dunas (e.g., Paim \& Scherer, 2003; Paim \& Scherer, 2007; Almeida et al., 2009; Trombetta et al., 2019), poucos trabalhos se dedicaram a compreender o comportamento da deposição eólica na margem desse sistema, comumente afetado pela sedimentação aluvial (Formação Pedra das Torrinhas) (Almeida et al., 2009; Marconato et al., 2009).

O presente trabalho se dedicou ao estudo faciológico e arquitetural em uma sucessão transicional entre os sistemas eólicos da Formação Pedra Pintada e não-eólicos da Formação Pedra das Torrinhas, margem leste do Grupo Guaritas (Bacia do Camaquã, RS) (Fig. 1). Os principais objetivos dessa pesquisa foram: identificar as associações de fácies e interpretá-las em termos paleoambientais e compreender a dinâmica eólica em um contexto pré-vegetação, comparando-a a exemplos modernos. Como resultado dos dados coletados, foi possível: (i) compreender as possíveis interações espaço-temporais de um campo de dunas, sem a interferência de cobertura vegetal, na borda de um rifte cambriano; (ii) propor um modelo de compartimentação paleoambiental mais refinado, responsável pela deposição da sucessão estudada. 

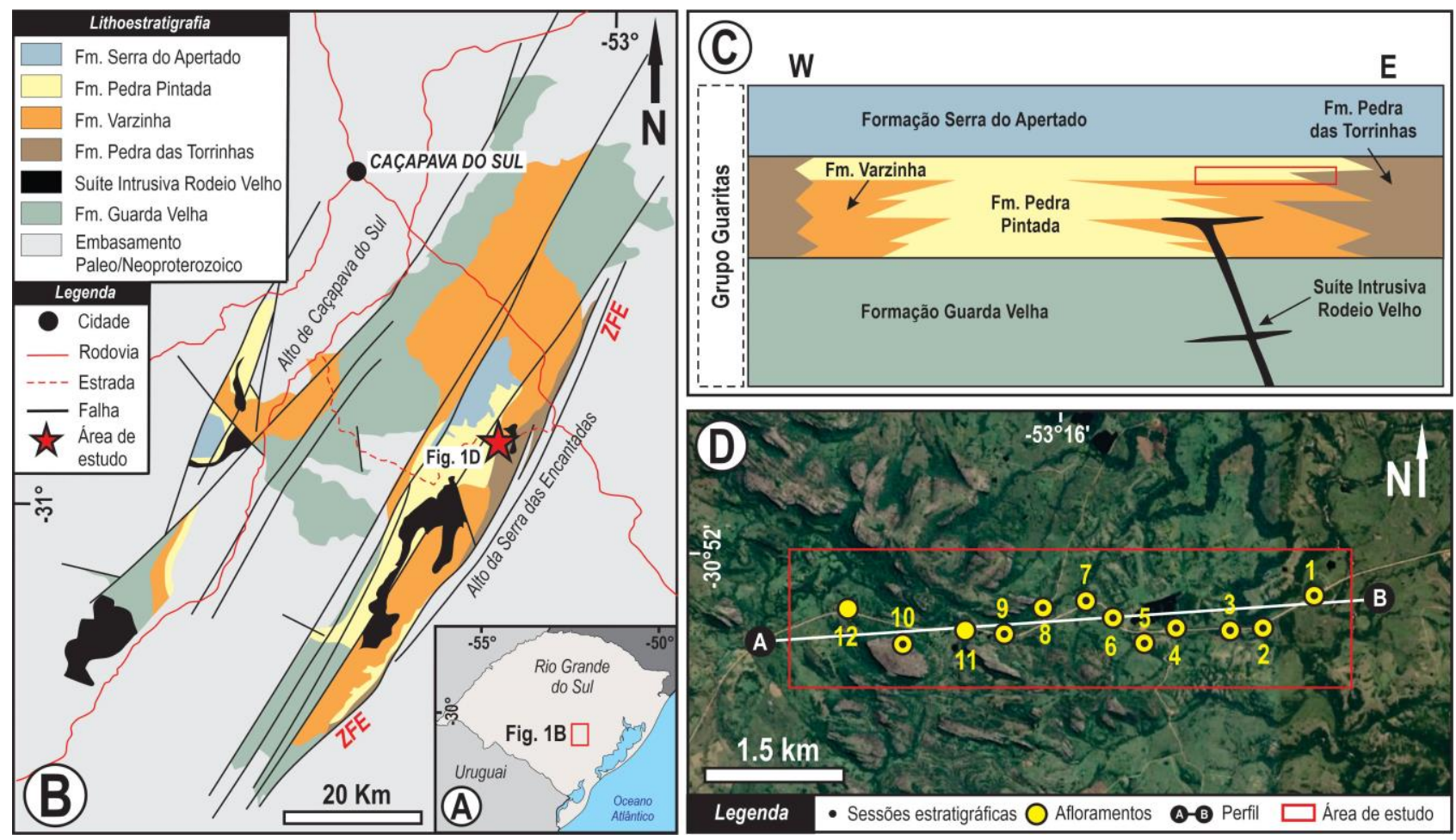

Figura 1. (A) Mapa geológico simplificado do Grupo Guaritas e localização da área de estudo (Modificado de Nóbrega et al., 2008), ZFE - Zona de falha Encantadas. (B) Localização geográfica do Grupo Guaritas (retângulo vermelho), porção centro-sul do Rio Grande do Sul (Brasil). (C) Empilhamento estratigráfico sumarizado do Grupo Guaritas (sem escala) (Modificado de Almeida et al., 2009). O retângulo vermelho indica o intervalo estratigráfico estudado (Google Earth Basemap, 2019). (D) Mapa de distribuição de pontos na área de estudo. O perfil A-B é apresentado na figura 2.

\section{CONTEXTO GEOLÓGICO E ÁREA DE ESTUDO}

\subsection{A Bacia do Camaquã}

A Bacia do Camaquã agrupa diferentes subbacias originadas durante períodos de acomodação e extensão tectônica do substrato paleo/neoproterozoico do Cinturão Dom Feliciano, centro-sul do Rio Grande do Sul (Fig. 1A, 1B) (Borba et al., 2008; Trombetta et al., 2019). Essa bacia abriga uma sucessão vulcano-sedimentar depositada em distintos ambientes tectônicos entre o Ediacarano e o Cambriano Inferior (600-530 Ma) (Paim et al., 2000; Almeida et al., 2010, Paim et al., 2014). Apesar das diferentes abordagens utilizadas na compartimentação estratigráfica da Bacia do Camaquã (e.g., Fragoso-Cesar et al., 2000; Paim et al., 2000; CPRM, 2008), o presente trabalho usa a divisão litoestratigráfica de acordo com Almeida (2005).
O registro estratigráfico da bacia apresenta uma espessura de sedimentos de aproximadamente $10 \mathrm{~km}$, dividida em quatro grupos (Paim et al., 2014). Essa subdivisão é baseada em diferentes estágios deposicionais da bacia, da base para o topo: (i) Grupo Maricá (depósitos marinhos rasos e deltaicos); (ii) Grupo Bom Jardim (depósitos fluviais em associação à atividade vulcânica); (iii) Grupo Santa Bárbara (depósitos fluviais associados a leques aluviais) e (iv) Grupo Guaritas (depósitos eólicos, fluviais e aluviais) (Almeida et al., 2009; Marconato et al., 2009; Godinho et al., 2013; Paim et al., 2014). Esses grupos foram depositados em pelo menos dois estágios tectônicos durante as fases finais de aglutinação do Supercontinente Gondwana Oriental pela Orogênese Brasiliana (Paim et al., 2014; Trombetta et al., 2019). Os Grupos Maricá e Bom Jardim possuem deposição associadas a um ambiente orogênico, provavelmente vinculados a bacias de retroarco e de pull-apart (Paim et al., 
2000; Borba et al., 2008). Por outro lado, os Grupos Santa Bárbara e Guaritas foram originados em um contexto anorogênico, durante eventos transtencionais (Bicca et al., 2013; Trombetta et al., 2019).

O Grupo Guaritas, objeto de estudo, consiste em uma sucessão cambriana depositada em um sistema de rifte de aproximadamente 50 $\mathrm{km}$ de largura e até $150 \mathrm{~km}$ de extensão (atual direção NNE-SSW), limitado pelos altos da Serra das Encantadas (leste) e Caçapava do Sul (oeste) (Almeida, 2005) (Fig. 1B). Esses altos estruturais representam expressões geomorfológicas de falhas normais de alto ângulo, limitando a bacia e o embasamento paleo/neoproterozoico do Cinturão Dom Feliciano (Marconato et al., 2009). O Grupo Guaritas compreende uma sucessão de natureza continental de aproximadamente 1000 m de espessura, dividida em cinco principais Formações, da base para o topo: (i) Guarda Velha (arenitos e conglomerados de origem fluvial); (ii) Pedra das Torrinhas (conglomerados de origem aluvial); (iii) Varzinha (depósitos deltaicos e fluviais); (iv) Pedra Pintada (arenitos eólicos) e (v) Serra do Apertado (arenitos e conglomerados de natureza fluvial) (Fig. 1C) (Godinho et al., 2013; Marconato et al., 2009; Paim et al., 2014; Paim \& Scherer, 2007). As Formações Pedra das Torrinhas, Varzinha e Pedra Pintada apresentam, geralmente, contatos interdigitados entre si (Fig. 1C). Esses depósitos são variavelmente afetados por intrusões de rochas básicas da Suíte Magmática Rodeio Velho $(547 \pm 6.2 \mathrm{Ma})$ (Hartmann et al., 1999; Almeida et al., 2000).

\section{2. Área de estudo}

A área de estudo está localizada no extremo leste do domínio do Grupo Guaritas, próxima ao alto das Serras das Encantadas (Fig. 1D). Esta área compreende os depósitos das Formações Pedra das Torrinhas e Pedra Pintada, interdigitados lateralmente (Fig. 1C), próximos à margem do rifte (Figuara $1 \mathrm{~B}$ ). A área de estudo foi selecionada em função (i) das exposições bem preservadas ao longo de uma área contínua e (ii) das mudanças laterais e verticais significativas das fácies sedimentares em pequena escala.

\section{MATERIAIS E MÉTODOS}

A análise de fácies foi realizada ao longo de um perfil (orientado W-E) (Fig. 1D) que engloba 12 principais afloramentos, onde foram realizados levantamentos de seções estratigráficas, fotomosaicos, painéis arquiteturais 2D e descrição detalhada dos depósitos (Fig. 2). Dez seções estratigráficas e quatro painéis arquiteturais foram construídos, proporcionando o reconhecimento de quatro associações de fácies. A individualização das fácies foi baseada em (i) diferentes estruturas sedimentares, (ii) características texturais e composicionais, (iii) padrão de paleocorrentes e (iv) geometria e espessura dos depósitos (Anderton, 1985; Walker, 2006). Devido à semelhança quantos as características litológicas de algumas associações de fácies, as estruturas sedimentares foram os principais atributos utilizados na compartimentação faciológica. A hierarquização de superfícies limitantes de acordo com a terminologia de Brookfield (1977) também foi utilizada para a caracterização dos depósitos eólicos.

Os dados de paleocorrentes foram obtidos a partir dos foresets das estratificações cruzadas. Após a correção do basculamento tectônico, os dados de paleocorrente foram plotados em diagramas de rosetas usando software Stereonet (versão 9.5). Estratos contendo depósitos de ripples de vento foram adotados como um datum topográfico das paleosuperfícies horizontais (ou subhorizontais), para fins de correção do basculamento tectônico (Abrantes Jr. et al., 2020; Mesquita et al., 2021). 


\section{ASSOCIAÇÃO DE FÁCIES}

\section{Foram reconhecidas quatro principais} associações de fácies na sucessão sedimentar analisada: (i) dunas eólicas (AF 1); (ii) interdunas secas (AF 2); (iii) lençóis de areia
(AF 3) e (iv) fluxos de detritos (AF 4) (Tab. 1). A arquitetura deposicional varia lateralmente, de leste a oeste, e verticalmente, em um intervalo estratigráfico de aproximadamente $60 \mathrm{~m}$ de espessura (Fig. 2).

Tabela 1. Sumário das fácies e associação de fácies descritas na sucessão sedimentar estudada.

\begin{tabular}{|c|c|c|c|c|}
\hline $\begin{array}{l}\text { Associação de } \\
\text { fácies }\end{array}$ & Litofácies & Descrição & Interpretação & $\begin{array}{l}\text { Agente de } \\
\text { transporte }\end{array}$ \\
\hline \multirow[t]{2}{*}{$\begin{array}{l}\text { Dunas eólicas (AF } \\
\text { 1) }\end{array}$} & $\begin{array}{l}\text { Arenitos com } \\
\text { estratificações } \\
\text { cruzadas de base } \\
\text { tangencial }\end{array}$ & \multirow{2}{*}{$\begin{array}{l}\text { Arenitos compostos por areias de } \\
\text { granulação média a fina, moderadamente } \\
\text { selecionados. Estratificações cruzadas } \\
\text { acanaladas e de base tangencial são as } \\
\text { principais estruturas sedimentares. Os sets } \\
\text { de estratificações cruzadas podem } \\
\text { apresentar até } 2 \text { m de espessura. }\end{array}$} & \multirow[t]{2}{*}{$\begin{array}{l}\text { Cadeias de dunas barcanóides } \\
\text { de crista sinuosa. Direção de } \\
\text { migração unidirecional para } \\
\text { E-SE. }\end{array}$} & Vento \\
\hline & $\begin{array}{l}\text { Arenitos com } \\
\text { estratificações } \\
\text { cruzadas acanaladas }\end{array}$ & & & \\
\hline \multirow[t]{2}{*}{$\begin{array}{l}\text { Interdunas secas } \\
\text { (AF 2) }\end{array}$} & Arenitos laminados & $\begin{array}{l}\text { Arenitos laminados compostos por areias } \\
\text { de granulação fina a grossa e organizados } \\
\text { em camadas lenticulares. Os grãos de areia } \\
\text { são organizados por uma gradação inversa } \\
\text { dentro das lâminas individuais. }\end{array}$ & $\begin{array}{l}\text { Depósitos de interdunas } \\
\text { originados em condições } \\
\text { secas pela deposição de } \\
\text { ripples de vento. }\end{array}$ & \\
\hline & $\begin{array}{l}\text { Arenitos laminados } \\
\text { com lentes de } \\
\text { argilito }\end{array}$ & $\begin{array}{l}\text { Arenitos laminados, compostos por areias } \\
\text { de granulação fina a grossa, intercalados } \\
\text { com finas lentes de argilito ( } 3 \text { a } 6 \text { mm de } \\
\text { espessura). }\end{array}$ & $\begin{array}{l}\text { Depósitos de interdunas } \\
\text { originados pelo } \\
\text { desenvolvimento de } \\
\text { pequenas superfícies de } \\
\text { adesão. }\end{array}$ & \\
\hline \multirow[t]{2}{*}{$\begin{array}{l}\text { Lençóis de areia } \\
\text { (AF 3) }\end{array}$} & $\begin{array}{l}\text { Arenitos com } \\
\text { estratificações de } \\
\text { baixo ângulo (<15ㅇ) }\end{array}$ & $\begin{array}{l}\text { Arenitos médios a muito grossos, } \\
\text { polimodais e com laminações plano- } \\
\text { paralelas (<15ㅇ) dispostos em camadas } \\
\text { tabulares que variam de } 0,13 \text { a } 1,7 \mathrm{~m} \text { de } \\
\text { espessura. }\end{array}$ & \multirow{2}{*}{$\begin{array}{l}\text { Migração de estratos } \\
\text { translatentes de marcas } \\
\text { onduladas eólicas (wind } \\
\text { ripples) em grandes } \\
\text { superfícies planas, } \\
\text { variavelmente associadas a } \\
\text { dunas pouco desenvolvidas } \\
\text { (zibars ou protodunas). }\end{array}$} & \\
\hline & $\begin{array}{l}\text { Arenitos com } \\
\text { laminações } \\
\text { horizontais }\end{array}$ & $\begin{array}{l}\text { Arenitos finos a muito grossos, com baixa } \\
\text { seleção e laminações horizontais, } \\
\text { organizados em camadas tabulares com } \\
\text { até } 2 \text { m de espessura. }\end{array}$ & & \\
\hline
\end{tabular}

Fluxos de detritos (AF 4)
Conglomerados clasto-suportados maciços
Conglomerados clasto-suportados maciços, com seixos polimíticos e imbricados. Essa fácies possui $15 \%$ de matriz composta por areias pobremente selecionadas (areia fina a areia muito grossa). Os depósitos são organizados em camadas lenticulares, comumente limitadas na base por uma pequena superfície erosiva.
Conglomerados matriz-suportados maciços
Conglomerados matriz-suportados maciços, com seixos polimíticos e polimodais estruturados em uma matriz de areia fina a grossa. Os corpos estão dispostos em camadas tabulares ou lenticulares que variam de poucos centímetros a vários metros de espessura.
Fluxos de detritos não-

Gravidade
Fluxo de detritos pouco coesivos 


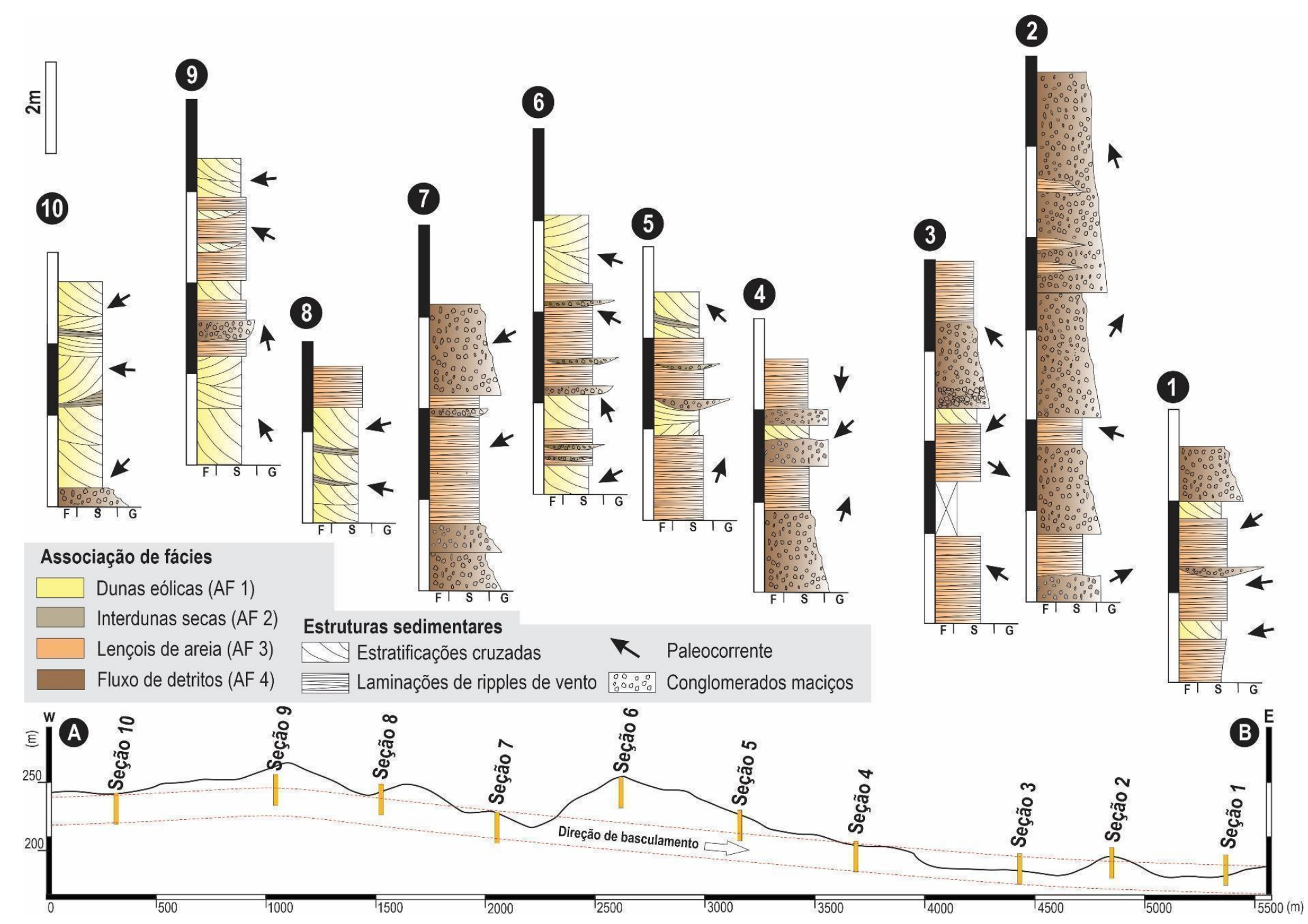

Figura 2. Seções estratigráficas e perfil esquemático mostrando: a distribuição dos elementos arquiteturais, as principais estruturas sedimentares, os padrões de paleocorrente e a direção de basculamento da sucessão estudada. A localização do perfil A-B é demonstrado na Figura 1C. 


\subsection{Associação de fácies de dunas eólicas (AF} 1)

\subsubsection{Descrição}

A associação de fácies de dunas eólicas consiste em arenitos de areias muito finas (> $0,062 \mathrm{~mm})$ a médias $(<0,5 \mathrm{~mm})$, compostos por grãos moderadamente selecionados, subarredondados e de moderada a alta esfericidade. Os arenitos possuem cores acinzentadas (Fig. 3A) a avermelhadas (Fig. 3B), como resultado da fina camada de óxido de ferro que envolve os grãos individuais. As principais estruturas sedimentares observadas são: estratificações cruzadas de base tangencial (Fig. 3C, D) e acanaladas (Fig. 4).

Nas seções paralelas ao paleotransporte, os corpos de arenitos são organizados em sets simples de geometria lenticular ou tabular com até $1,8 \mathrm{~m}$ de espessura e 10 a $30 \mathrm{~m}$ de continuidade lateral. Os foresets apresentam base tangencial e mergulhos de alto ângulo $\left(15^{\circ}\right.$ a $\left.22^{\circ}\right)$ no intervalo estudado (Fig. 3A). Cunhas de arenitos maciços (> $65 \%$ ) e de arenitos com laminações de ripples de vento (<35\%) ocorrem interdigitadas na base das estratificações cruzadas (Fig. 3B). As cunhas de arenitos maciços possuem espessura entre 15 e $35 \mathrm{~mm}$ e as cunhas de laminações de ripples de vento (wind ripple strata) apresentam espessuras entre 5 e $12 \mathrm{~mm}$, internamente organizadas por uma gradação inversa entre areias de granulação fina e grossa.

Os sets de estratificações cruzadas de base tangencial são organizados em cosets de até 6 $m$ de espessura (Fig.2), na maioria das vezes interestratificados com os depósitos de interdunas (Figs. 3C e 3D), descritos adiante. Os contatos entre esses depósitos podem ocorrer de três diferentes formas: abrupto, transicional e interdigitado (Figs. 3C e 3D). O contato abrupto é representado por uma superfície erosiva, plana e de baixo ângulo $(<15$ o) de até $30 \mathrm{~m}$ de extensão, que, em geral, limita a base e o topo entre os sets de estratificações cruzadas. O contato transicional caracteriza-se pela progressiva redução do ângulo de mergulho dos foresets em seções paralelas ao paleotransporte, tornando as cunhas de ripples de vento gradativamente mais espessas. Não obstante, o contato interdigitado representa a alternância cíclica entre o toeset dos estratos cruzados sobrejacentes, compostos por cunhas de fluxo de grãos, e os depósitos de interdunas, majoritariamente constituído por laminações de ripples de vento (Figs. $3 \mathrm{C}$ e 3D).

Nas seções perpendiculares ao paleotransporte, as estratificações cruzadas acanaladas são comuns (Figs. 4A e 4B). Os corpos de arenitos são organizados por sets em forma de cunha e de base côncava, de 2 a $4 \mathrm{~m}$ de largura e 1 a $2 \mathrm{~m}$ de espessura, formando cosets de até $6 \mathrm{~m}$ de espessura e $30 \mathrm{~m}$ de extensão lateral (Figs. 4A e 4B). As cunhas são preenchidas por foresets em arranjo levemente simétrico em relação ao eixo central do set, comumente erodidas ao topo por novas cunhas de estratos acanalados ou por lentes de conglomerados maciços da associação AF 4 (Fig. 4).

As estratificações cruzadas apresentam distribuição unimodal, com valor médio para 260ㅇa azimute e alto espalhamento das direções dos estratos cruzados (110 a $040^{\circ}$ ) (Fig. 5). Variavelmente, superfícies erosivas que truncam os foresets no interior de um mesmo set são observáveis. Essas superfícies possuem geometria levemente côncava, separando e truncando conjuntos de foresets em ângulos ligeiramente oblíquos entre si (Fig. 3D). 


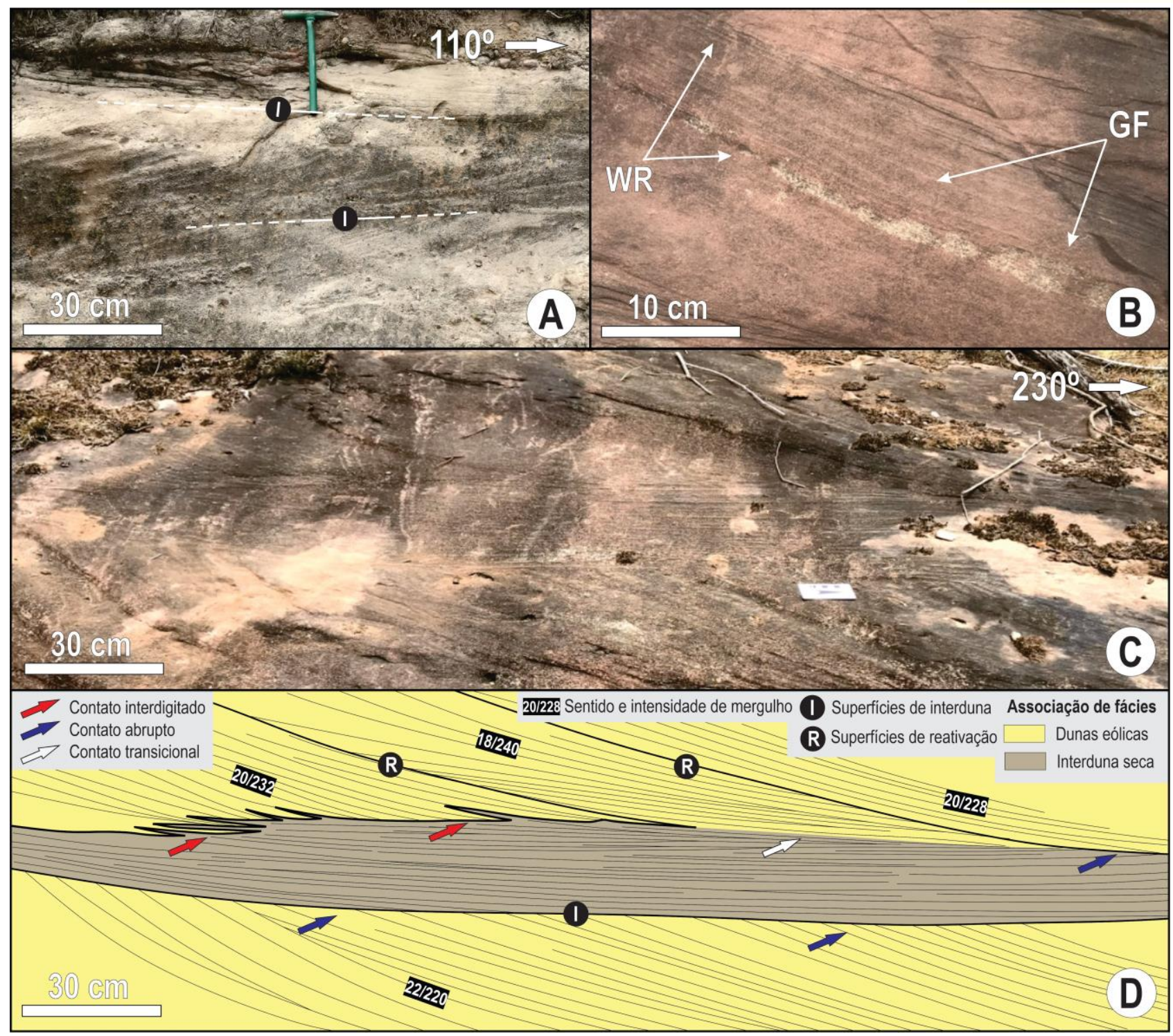

Figura 3. (A) Sets tabulares contendo estratificações cruzadas de base tangencial. A base e topo dos sets individuais geralmente é limitada por uma superfície suavemente plana e de baixo ângulo, reconhecida como uma superfície de interduna. (B) Interdigitação entre cunhas de fluxo de grãos (GF - grainflow strata) e laminações de ripples de vento (WR - wind-ripple lamiane) na base dos foresets. (C) Fotografia e (D) sketch demonstrando as relações de contato entre a associação de fácies de dunas eólicas e interdunas. O contato transicional demonstra uma redução progressiva do ângulo de mergulho dos foresets, modificando-se para os depósitos de interdunas. O perfil da fotografia se concentra paralelo ao trend de paleotransporte 


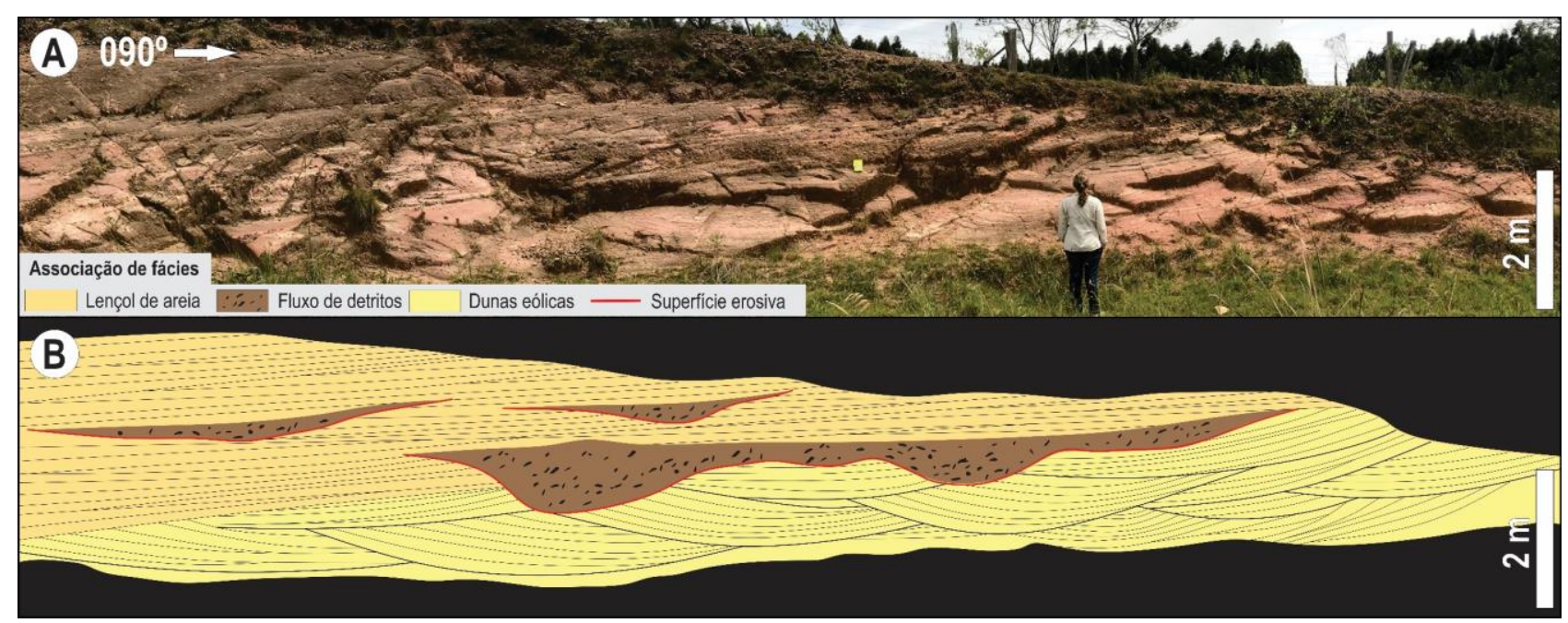

Figura 4. (A) Fotomosaico e (B) painel arquitetural em seção perpendicular ao paleotransporte. Os depósitos de dunas eólicas são representados por estratificações cruzadas acanaladas, limitadas ao topo pelos depósitos de lençóis de areia e fluvial. O topo dos cosets que contém os depósitos eólicos são limitados por superfícies erosivas côncavas e irregulares (linha vernelha), as quais definem a base das camadas contendo a associação de fácies fluviais.

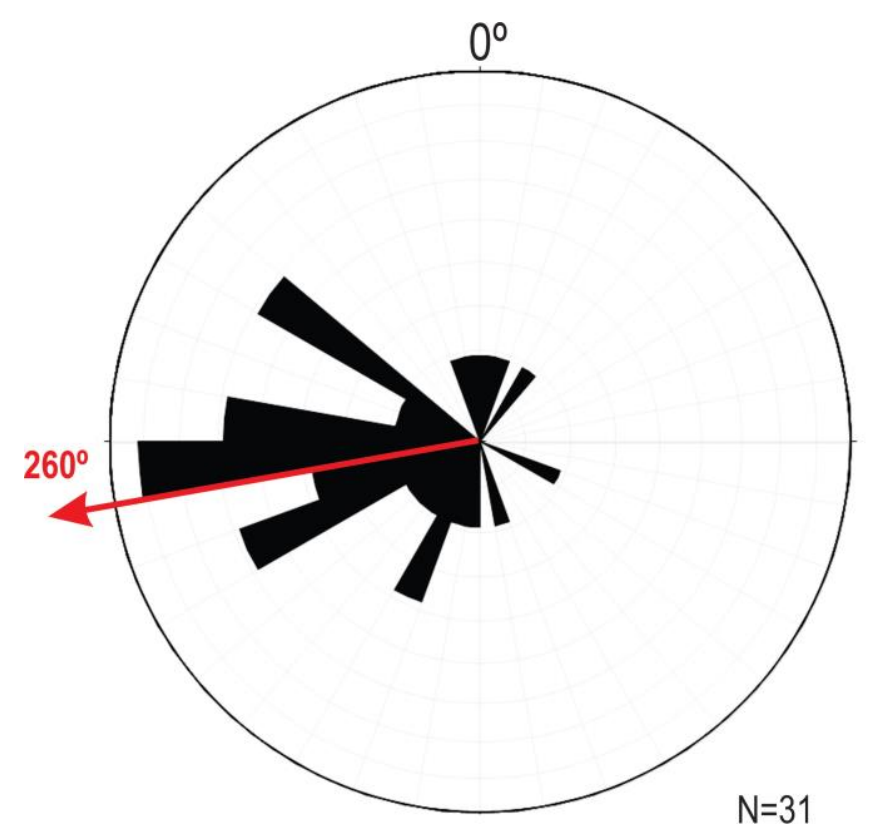

Figura 5. Diagrama de roseta contendo a distribuição dos foresets de estratificação cruzada. As direções de paleocorrente fornecidas por esse dado implicam em padrão unidirecional de migração das dunas, com valor médio para 260 azimute (seta vermelha). Observe o alto espalhamento da direção de mergulho dos foresets.

\subsubsection{Interpretação}

A presença de corpos de arenitos compostos por grãos bem selecionados e dispostos em conjuntos simples de estratificações cruzadas de grande porte (tangenciais na base e acanaladas) sugerem depósitos originados pela migração de dunas eólicas simples (Hunter, 1977; Mountney, 2006a). As cunhas de arenitos maciços que compõem as estratificações cruzadas são interpretadas como depósitos de fluxo de grãos (grainflow strata), originadas a partir do processo de avalanche na face frontal das dunas (Hunter, 1977). A predominância do fluxo de grãos depositados nas partes mais baixas dos estratos cruzados indicam dunas com faces de avalanche bem desenvolvidas, 
provavelmente entre 20 e $50 \mathrm{~m}$ de altura, de acordo com modelos empíricos de Kocurek \& Dott (1981).

Os diferentes tipos de contatos que delimitam os sets de estratificações cruzadas estão associados a diferentes condições de migração e acumulação eólica durante a atividade da duna (Mountney, 2006b; Jones et al., 2016). As superfícies limitantes erosivas e quase horizontais que representam os contatos abruptos consistem nas superfícies limitantes de primeira ordem de Brookfield (1977), interpretadas como superfícies interdunares (Kocurek, 1981, 1988). Essas superfícies são originadas em períodos de altas taxas de erosão de interdunas em função da contínua migração e escalada de dunas eólicas em condições secas (Kocurek, 1981; Kocurek, 1988; Mountney \& Jagger, 2004). Por outro lado, o contato gradacional sugere uma migração síncrona de dunas e interdunas, enquanto os contatos interdigitados representam variações na taxa de erosão de interdunas devido a mudanças no ângulo de inclinação das faces de avalanche das dunas sobre os planos interdunares adjacentes (Pulvertaft, 1985; Jones et al., 2016). Essa característica sugere uma usual mudança das condições morfodinâmicas da duna (e.g., velocidade de migração e/ou altura), permitindo a redução periódica no seu ângulo de escalada e a expansão das áreas interdunares (Mountney, 2006b, 2012). A frequente presença desses contados na base das estratificações cruzadas podem estar relacionadas (i) a ciclicidade da disponibilidade de areia para a manutenção e construção da duna ou (ii) de flutuações na capacidade de transporte pelo vento (Mountney, 2006a). Em geral, essas condições são atribuídas a sazonal influência do lençol freático em áreas adjacentes e/ou internas ao campo de dunas, modificando espacialmente a saturação do vento e, portanto, as taxas de construção e migração das dunas eólicas (Mountney \& Thompson,
2002; Mountney \& Jagger, 2004, Mountney, 2006b).

A geometria das estruturas acanaladas nas seções perpendiculares ao paleotransporte propõe a migração de dunas eólicas assimétricas e com crista sinuosa, segundo modelos computacionais propostos por Rubin e Carter (2006). A alta dispersão na direção dos foresets também corroboram com essa hipótese (Scherer, 2000). Por sua vez, o padrão unidirecional das paleocorrentes propõe que os depósitos de dunas eólicas foram provavelmente originados por dunas barcanóides (Kocurek, 1991; Lancaster, 1982).

As superfícies erosivas que truncam os foresets no interior de um mesmo set representam as superfícies de terceira ordem de Brookfield (1977), definidas como superfícies de reativação (Kocurek, 1991). Essas superfícies são originadas por flutuações na velocidade e/ou direção do vento principal durante a migração da duna, processo usual em sistemas eólicos modernos (Mountney, 2006a, Al-Masrahy \& Mountney, 2013). 


\subsection{Associação de fácies de interdunas secas (AF 2)}

\subsubsection{Descrição}

Essa associação de fácies compreende corpos de arenitos laminados compostos por areias finas $(>0,125 \mathrm{~mm})$ a grossas $(<1,0 \mathrm{~mm})$. Os grãos apresentam moderado grau de seleção, arredondamento e esfericidade, bem como uma superfície fosca. As lâminas individuais são planas a sub-horizontais (< 05) e apresentam espessuras entre 3 e $8 \mathrm{~mm}$, internamente organizadas por grãos em gradação inversa (Figs. 6A e 6B). Assim como os arenitos da associação de fácies de dunas eólicas, esses depósitos apresentam coloração avermelhada ocasionada por finas camadas de óxido de ferro que envolvem os grãos de areia (Fig. 6A). Localmente, os arenitos laminados ocorrem intercalados com finas lentes de argilitos, de 3 a $6 \mathrm{~mm}$ de espessura, que apresentam uma coloração esverdeada à acinzentada (Fig. 6C).

Os arenitos laminados são organizados em camadas lenticulares de 0,4 a 0,8 m de espessura e 2 a $8 \mathrm{~m}$ de largura, em seções paralelas ao paleotransporte (Figs. $3 C$ e D). Esses estratos costumam ocorrer interestratificados com os depósitos de dunas eólicas, exibindo contatos abruptos, transicionais ou interdigitados, conforme descrito em detalhe na seção 4.1.

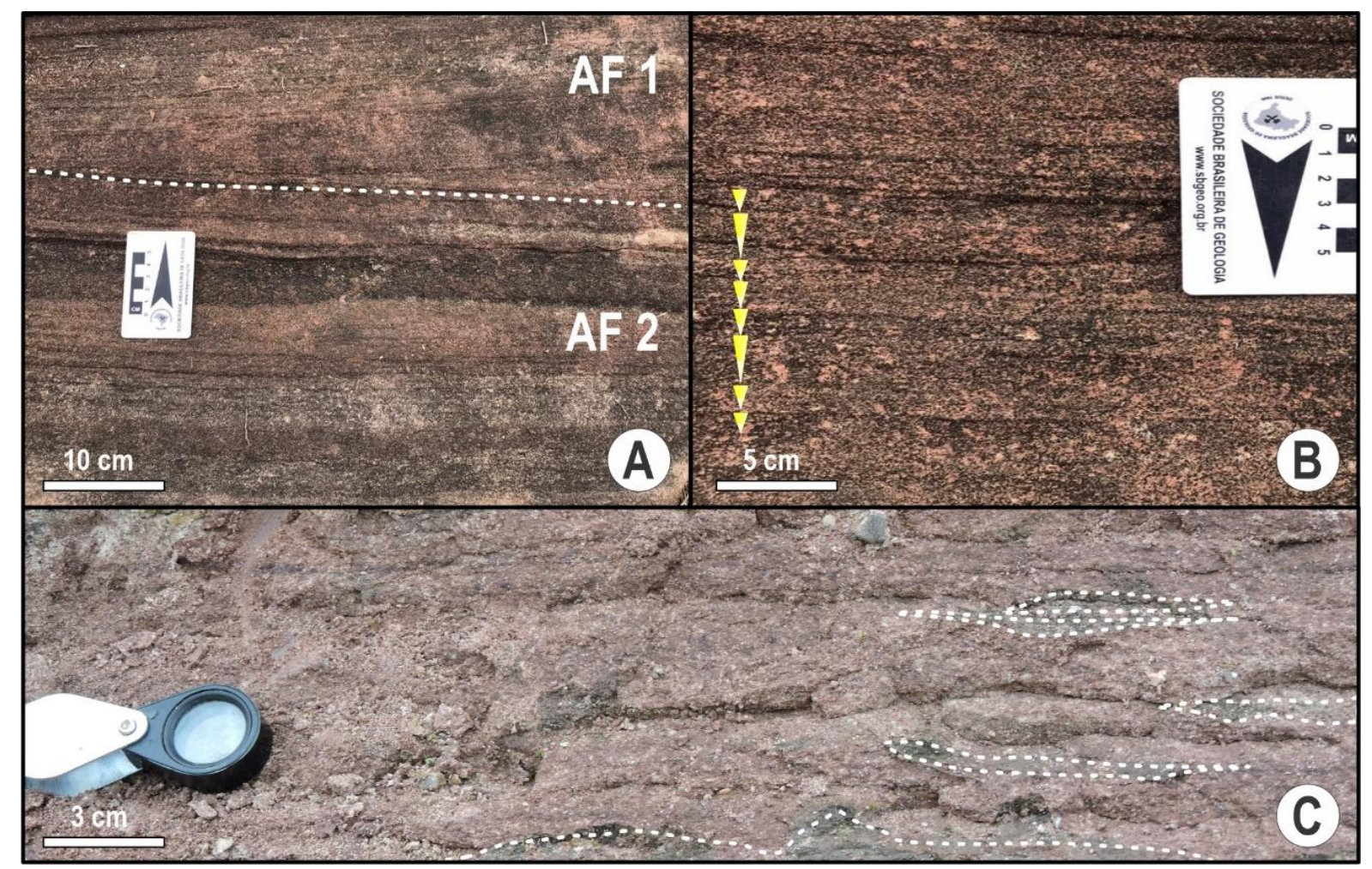

Figura 6. (A) Arenitos com laminações horizontais da associação de fácies de interdunas secas (AF 2). As laminações são interpretadas como depósitos de ripples de vento, sedimentadas em áreas interdunares. Na imagem, essa associação de fácies é sobreposta por um contato abrupto (linha tracejada branca) e por estratificações cruzadas de dunas eólicas. (B) Visão em detalhe das laminações horizontais, onde os grãos de areia são organizados por uma gradação inversa ascendente. (C) Arenitos laminados intercalados de finas lentes de argilito. Os limites aproximados das lentes de argilito são destacados pelas linhas pontilhadas brancas.

\subsubsection{Interpretação}

Os arenitos laminados compostos por grãos de moderado grau de seleção, arredondamento e esfericidade, sugerem depósitos transportados pelo vento. As superfícies foscas dos grãos corroboram com essa interpretação, uma vez que o constante impacto entre os sedimentos durante o transporte eólico as imprime nas partículas de areia (Hunter, 1977; Mountney, 2006a). As 
lâminas planas e de baixo ângulo, internamente organizadas por uma gradação inversa, implicam em depósitos originados por ripples de vento (wind ripples) sobre uma superfície deposicional seca e plana (Ahlbrandt \& Fryberger, 1981; Fryberger et al., 1992). A frequente intercalação desses estratos com depósitos de dunas eólicas, propõe uma sedimentação desenvolvida em áreas de interdunas (Ahlbrandt \& Fryberger, 1981).

A presença de finas lentes de argilito intercaladas a esses depósitos pode indicar o desenvolvimento de pequenas superfícies de adesão nas áreas de interduna (Mountney, 2006b). As superfícies de adesão são originadas pela presença de umidade na superfície deposicional, produzindo o aprisionamento de sedimentos de granulação fina (silte e argila), geralmente transportados em suspenção pelo vento, no substrato interdunar (Mountney, 2006a, Kocurek and Day, 2018). Entretnato, essas feições são pouco distribuídas nos depósitos da AF 2, sugerindo que a sedimentação eólica nas áreas de interdunas ocorreu majoritariamente em condições secas.

\subsection{Associação de fácies de lençóis de areia (AF 3)}

\subsubsection{Descrição}

A associação de fácies de lençóis de areia consiste em arenitos de areias finas $(>0,125$ $\mathrm{mm})$ a muito grossas $(<2,0 \mathrm{~mm})$, compostos por grãos com moderado grau de seleção e com baixo arredondamento e esfericidade. Os arenitos possuem cores acastanhadas à avermelhadas (Figs. 7 e 8). No intervalo estudado, os corpos de arenitos são organizados em camadas de geometrias tabulares que variam de 0,5 a $3 \mathrm{~m}$ de espessura, alcançando até $20 \mathrm{~m}$ de continuidade lateral em seções paralelas ao paleotransporte (Figs. 7A e 7B). As principais estruturas sedimentares observadas são as estratificações cruzadas de baixo ângulo (< 12ㅇ) e laminações horizontais (Figs. 7A e 7B).

Os arenitos com estratificações cruzadas de baixo ângulo são organizados em sets tabulares de 0,3 a 1,2 de espessura e até 10 $\mathrm{m}$ de continuidade horizontal (Figs. 7A e 7B). Esses arenitos compreendem aproximadamente $20 \%$ da espessura total da associação de fácies de lençol de areia. Os arenitos com laminações horizontais são os mais abundantes na sucessão estudada ( 80 $\%$ da espessura dessa associação de fácies). Essas camadas possuem geometrias tabulares que alcançam até $2,5 \mathrm{~m}$ de espessura e $20 \mathrm{~m}$ de extensão lateral em seções paralelas ao paleotransporte (Fig. 7). As lâminas individuais apresentam espessuras entre 2 e 8 mm, em que os grãos são organizados a partir de uma gradação inversa, tais como os depósitos laminados da associação de fácies AF 2 (Fig. 8A). Ocasionalmente, fragmentos de rocha, geralmente nas frações grânulo (2 $4 \mathrm{~mm}$ ) e seixo (4 - $64 \mathrm{~mm}$ ), são distribuídos de forma esparsa entre os arenitos laminados (Fig. 8B). Os fragmentos de rocha tornam-se progressivamente mais arredondados $\mathrm{e}$ esféricos nos depósitos do perfil estudado, de leste a oeste, onde é comum a presença de seixos de ventifactos (Fig. 8C). Localmente, marcas onduladas (ripples de onda) podem ser observadas em associação a esses depósitos. Em vistas planas, essas estruturas exibem linha de crista sinuosa, espaçadas regularmente entre 60 e $80 \mathrm{~mm}$ (Fig. 8D).

A associação de fácies de lençol de areia ocorre frequentemente interestratificada com os depósitos de fluxo de detritos (AF 4), a leste do perfil, a partir de contatos erosivos e abruptos (Fig. 4). Eventualmente são observadas interestratificações com os sets lenticulares da associação de fácies de dunas eólicas, a oeste do perfil (Fig. 2). 


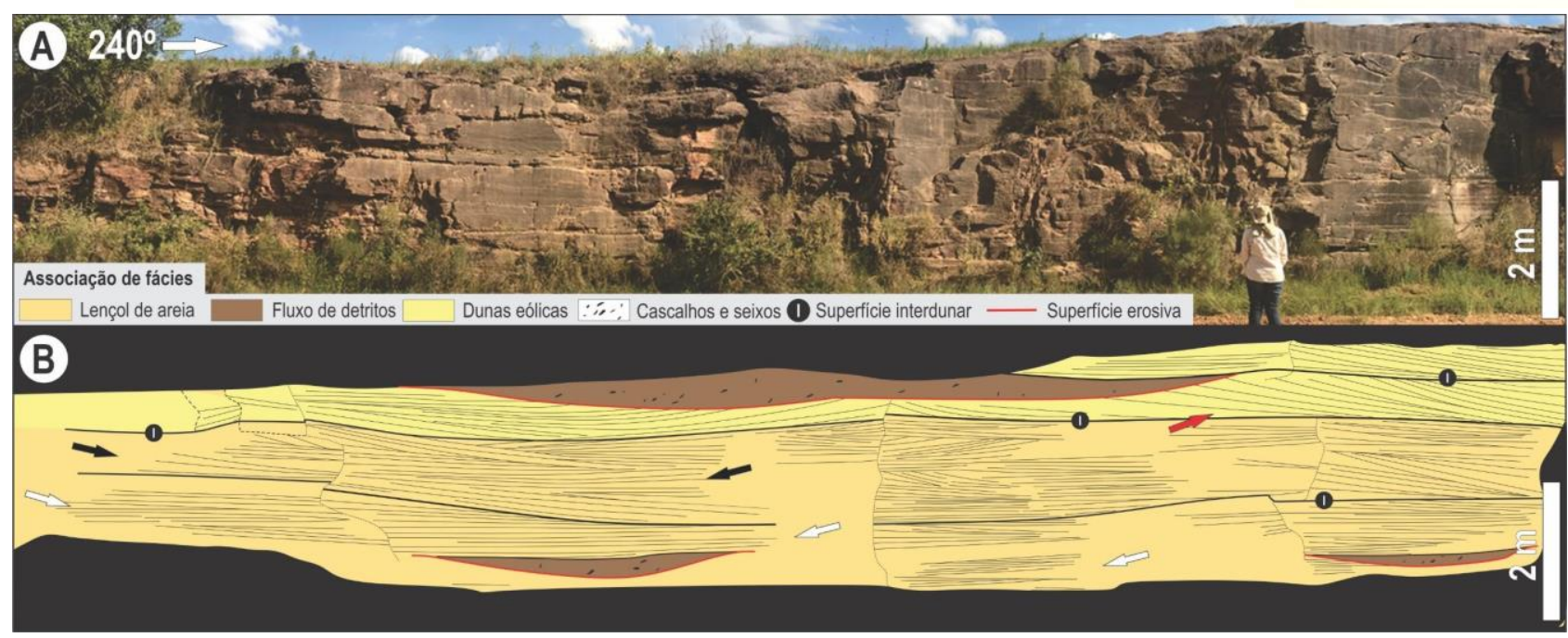

Figura 7. (A) Fotomosaico e (B) painel arquitetural em seção oblíqua ao paleotransporte. Os depósitos da associação de fácies de lençol de areia são constituídos por arenitos com estratificações cruzadas de baixo ângulo (setas pretas) e arenitos com laminações horizontais (setas brancas). As fácies de dunas eólicas (setas vermelhas) e de fluxos de detritos podem ocorrer interestratificados a essa associação de fácies. A associação AF 4 geralmente ocorre na forma de lentes com base côncavas e erosivas (linha vermelha) e topos definidos por contatos gradacionais.

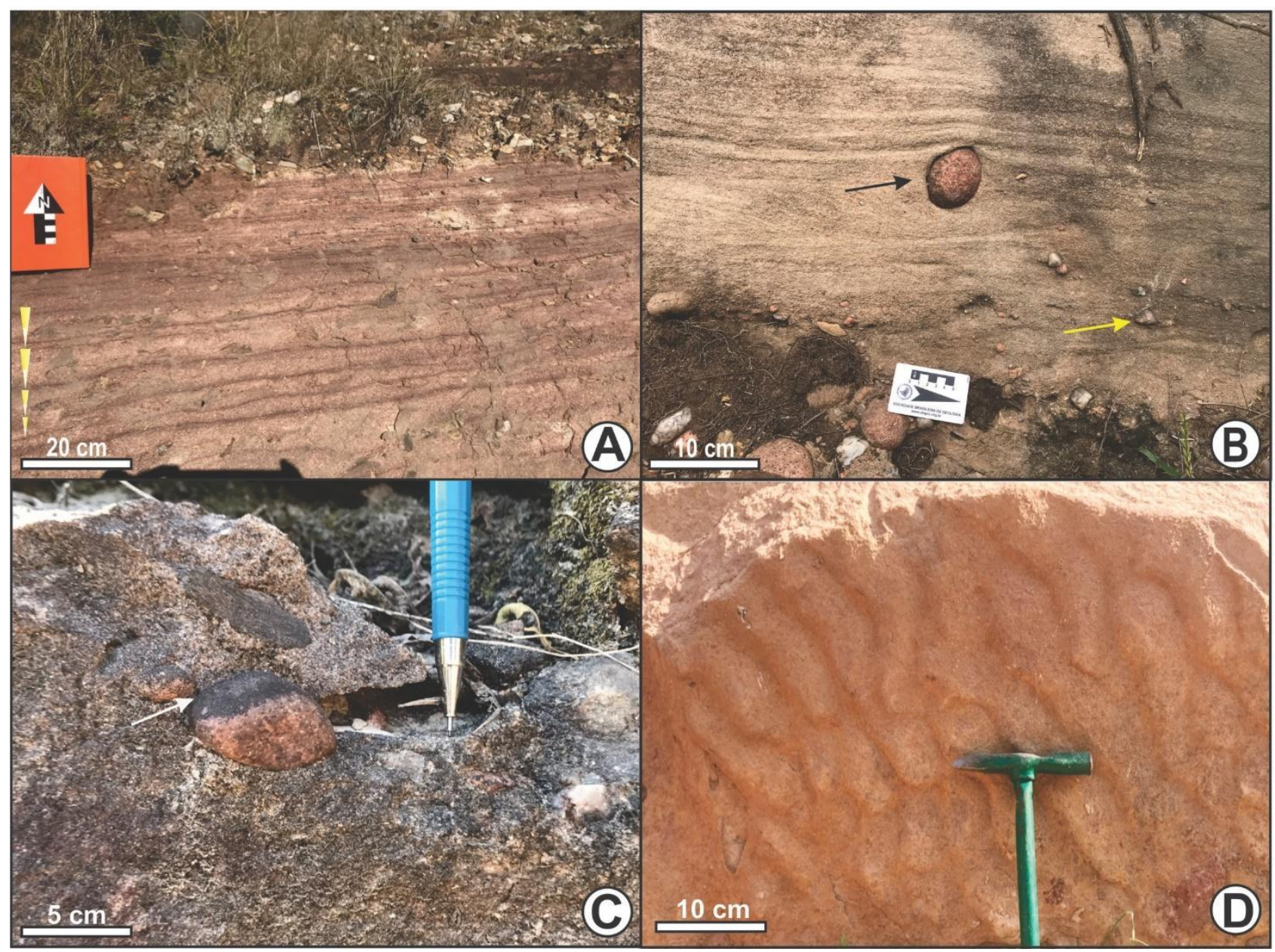

Figura 8. Depósitos da associação de fácies de lençol de areia. (A) Arenitos compostos por laminações horizontais, constituídas por uma gradação inversa entre areia fina a grossa. Esses arenitos são originados pela migração de estratos translatentes de marcas onduladas eólicas (wind ripples). (B) fragmentos de rocha nas frações grânulo (seta amarela) e seixo (seta preta) distribuídos de forma esparsa nos arenitos laminados. (C) Seixo de ventifacto originado pelo retrabalhamento eólico. (D) Marcas onduladas (ripples de onda), exibindo linhas de crista sinuosa e espaçamento regular entre 60 e $80 \mathrm{~mm}$. 


\subsubsection{Interpretação}

A grande extensão lateral de camadas de arenitos laminados de baixo ângulo, predominantemente compostos por laminações com gradação inversa, é interpretada como depósitos originados pela deposição de ripples de ventos em extensas superfícies planas (Hunter, 1977; Fryberger et al., 1979). Os arenitos organizados em sets de estratificações cruzadas de baixo ângulo são interpretados como depósitos de dunas eólicas isoladas e com faces de avalanche pouco desenvolvidas, tais como dunas zibars (ou protodunas) (Kocurek \& Nielson, 1986, Nielson \& Kocrek, 1986, Basilici \& Dal'Bó, 2014). Deste modo, é possível atribuir essa associação de fácies a um ambiente eólico com (i) limitado desenvolvimento de dunas eólicas e (ii) predominante deposição por ripples de vento, como áreas de lençóis de areia (Fryberger et al., 1979; Clemmensen \& Dam, 1993; Biswas, 2005).

O sistema de lençóis de areia provavelmente foi desenvolvido em condições predominantemente secas, conforme indicado pela deposição dominante de estratos de ripples de vento (Kocurek \& Nielson, 1986; Mountney, 2006a). Entretanto, os arenitos com marcas onduladas indicam uma origem por fluxos oscilatórios em áreas inundadas (Bagnold, 1946; Allen, 1979), no qual o espaçamento regular das ondulações propõe um período de onda constante no leito plano (Bagnold, 1946; Collinson \& Mountney, 2019). Essas características sugerem o desenvolvimento de superfícies encharcadas, como pequenas lagoas rasas, vinculadas ao ambiente de lençóis de areia (Mountney, 2006b). Apesar de estruturas como ripples de adesão não serem observadas na sucessão estudada, trabalhos anteriores de Paim \& Scherer (2003) e Paim \& Scherer (2007) em áreas contíguas sugerem uma frequente influência do lençol freático sobre as superfícies deposicionais secas desse sistema eólico. Logo, flutuações no lençol freático provavelmente resultaram na geração de pequenas superfícies úmidas, limitando a disponibilidade de areia para a geração de grandes dunas eólicas nesse sistema (Mountney \& Thompson, 2002).

Os níveis de seixos e grânulos de fragmentos de rochas demonstram uma deposição próxima à área fonte, comuns em lençóis de areia intermontanos (Basilici \& Dal'Bó, 2014; Dal'bó \& Basilici, 2015). Outra hipótese é o desenvolvimento de zonas deflacionárias no interior desses sistemas em função da alta energia do vento efetivo em detrimento ao aporte sedimentar (Mountney, 2006a). No entanto, a gradação longitudinal do arredondamento e esfericidade desses fragmentos, de leste a oeste do perfil, propõe: um gradual distanciamento do sistema em relação a área fonte e a progressiva dominância dos processos eólicos, proporcionando o maior retrabalhamento dos clastos e formação de ventifactos (Blair \& McPherson, 2009, Tsoar \& Pye, 2009). As relações estratigráficas dessa associação de fácies também corroboram com essa hipótese, uma vez que os depósitos de dunas eólicas estão concentrados na margem oeste do perfil estudado. 


\subsection{Associação de fácies de fluxo de detritos (AF 4)}

\subsubsection{Descrição}

A associação de fácies de fluxos de detritos compreende conglomerados compostos por grãos nas frações grânulo $(2-4 \mathrm{~mm})$ a seixo $(30-80 \mathrm{~mm}$ ) pobremente selecionados, com baixo a moderado grau de arredondamento e de baixa esfericidade. Esses fragmentos são de natureza polimítica (e.g., quartzitos, xistos e gnaisses) (Fig. 10A) e compõem duas principais fácies: (i) conglomerados clastosuportados maciços e (ii) conglomerados matriz-suportados maciços (Figs. 10B, 10C)

Os conglomerados clasto-suportados maciços são dispostos em camadas lenticulares que variam de 0,2 a 2,0 m de espessura e até $9 \mathrm{~m}$ de extensão lateral na área de estudo (Figs. 4 e 7). O arcabouço corresponde a aproximadamente $85 \%$ do volume dessa litofácies, onde pontualmente é possível observar seixos imbricados. A matriz ( 15\% do volume total) é composta por grãos de areia fina a muito grossa, pobremente selecionados, de baixo arredondamento e esfericidade. As camadas comumente apresentam uma base côncava ou irregular, limitadas por pequenas superfícies erosivas (até $2 \mathrm{~m}$ de continuidade horizontal) e por topos planos ou ondulados (Figs. 4 e 7). Essas superfícies limitam a litofácies, que ocorre preferencialmente nos níveis intermediários da sucessão analisada (Fig. 2). Os principais contatos dessa fácies ocorrem com os depósitos da associação de fácies de lençóis de areia (Figs. 2 e 7). Esses contatos são granodecrescentes para o topo quando sobrepostos por arenitos eólicos. Localmente, são observados contatos abruptos com os depósitos da associação de fácies de dunas eólicas (Fig. 7) e interdigitações com a litofácies de conglomerados matrizsuportados, descrita a seguir.

Os conglomerados matriz-suportados maciços estão frequentemente organizados em camadas tabulares, e, eventualmente lenticulares, de 0,5 a $5 \mathrm{~m}$ de espessura e de até $20 \mathrm{~m}$ de extensão lateral (Fig. 9). Os seixos estão dispostos de maneira caótica em uma matriz de areia média a muito grossa ( 60\% do volume total da litofácies), pobremente selecionada e de baixa esfericidade (Fig. 10C). A litofácies de conglomerados matrizsuportados maciços é observada em todos os intervalos estratigráficos da sucessão estudada, embora seu predomínio ocorra preferencialmente na porção leste da área de estudos (Fig. 2). Os contatos abruptos são os mais comuns e estão frequentemente associados aos depósitos da associação de fácies de lençóis de areia (Fig. 10 D), que ocorrem a partir de extensas superfícies erosivas, entre 8 e $20 \mathrm{~m}$ de continuidade lateral (Fig. 9). Contatos abruptos também são observados com os depósitos de dunas eólicas, mas em menor frequência (Fig. 7). 


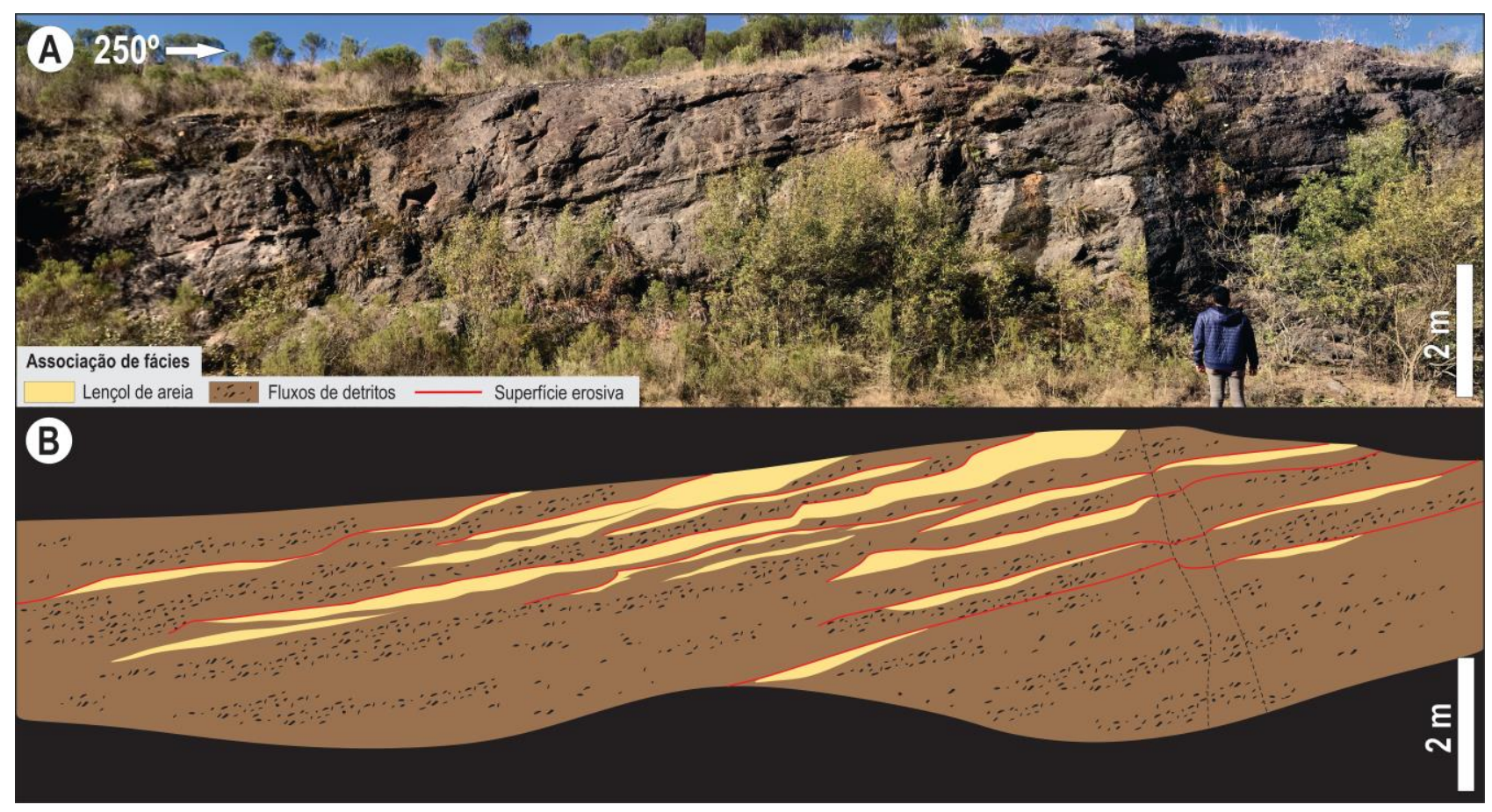

Figura 9. (A) Fotomosaico e (B) painel arquitetural exibindo os depósitos da associação de fácies de fluxo de detritos (AF 4). Os depósitos da associação AF 4 são espessos e organizados em camadas tabulares. Lentes contendo os arenitos da associação de fácies de lençol de areia podem ocorrer interestratificados, geralmente limitados por uma superfície erosiva (linha vermelha). Essa sucessão provavelmente foi depositada em zonas próximas à área fonte, onde a deflação eólica ocorria imediatamente após o término dos eventos de fluxo de detritos.

\subsubsection{Interpretação}

Os conglomerados clasto-suportados maciços e conglomerados matriz-suportados maciços associados a ausência de organização interna e a presença de uma matriz arenosa sugerem que a deposição dos sedimentos se deu a partir de fluxos gravitacionais, tais como fluxo de detritos (Namec \& Stell, 1984; Blair \& McPherson, 1994, Calhoun \& Clague, 2018). Nestes fluxos, uma massa viscosa de detritos, ar e água (promovida pelas condições de precipitações intensas e/ou prolongadas) se move gravitacionalmente até que a força de atrito do substrato seja igual a energia cinética da mistura, cessando o seu transporte e depositando o material (Hooke, 1987; Blair, 2001). A falta de turbulência do fluxo impede a classificação granulométrica dos sedimentos e não permite a orientação dos clastos, que são depositados de maneira desorganizada e sem estruturas primárias (Blair \& McPherson, 1998; Nichols, 2009), explicando assim, o aspecto maciço das fácies conglomeráticas descritas. A relação matriz e arcabouço desses depósitos propõem que conglomerados clasto-suportados maciços foram originados por fluxos de detritos nãocoesivos e pseudo-plásticos, enquanto os conglomerados matriz-suportados maciços, por fluxo de detritos pouco coesivos (Blair \& McPherson, 1994; Mulder \& Alexander, 2001; Nichols, 2009, Calhoun \& Clague, 2018).

As geometrias tabulares dos depósitos implicam a atividade desses fluxos em superfícies não confinadas, enquanto a geometria lenticular provavelmente está relacionada à deposição desses fluxos em canais incisos secos situados próximo à área de deposição primária (Blair, 1987; Benda, 1990; De Haas, 2014). As intercalações com os pacotes areníticos da associação de fácies de lençóis de areia demonstram ainda o desconfinamento e a cessação lateral dos fluxos da associação $\mathrm{AF}$ 4, provavelmente relacionados a redução do gradiente topográfico e a perda de água por evaporação (Batezelli \& Basilici, 2016). 
Por sua vez, as superfícies erosivas que limitam a base desses depósitos indicam o alto poder erosivo desses fluxos, geralmente erodindo substratos acumulados pelo vento, assim como indicado pelas relações estratigráficas da sucessão estudada (Calhoun \& Clague, 2018). A alta concentração de fragmentos de rochas e a angulosidade dos grãos sugerem uma deposição próxima a área fonte (Nichols, 2009).

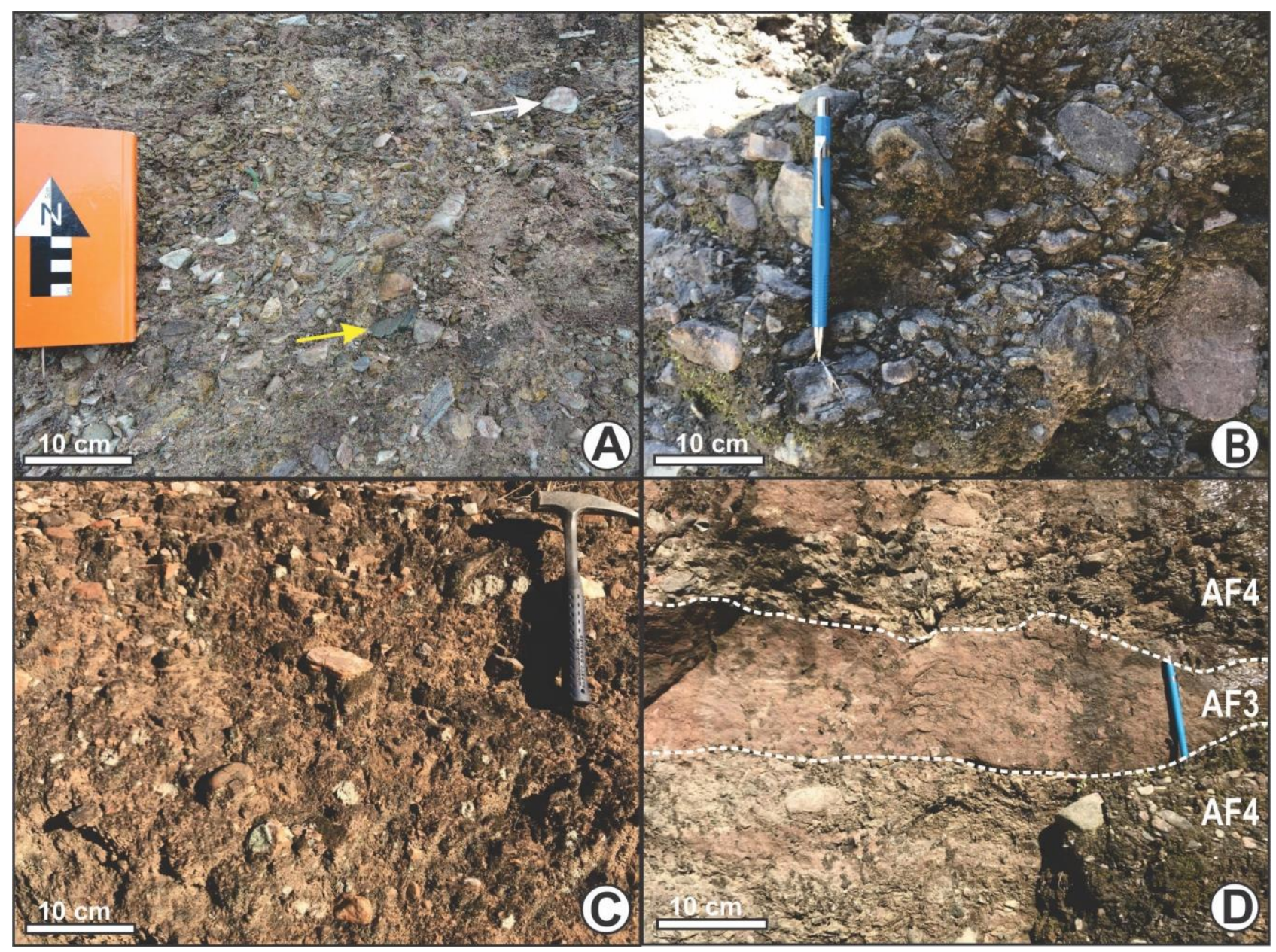

Figura 10. Depósitos da associação de fácies de fluxo de detritos (AF 4). (A) Conglomerados polimíticos com clastos pobremente selecionados e de baixo a moderado grau de arredondamento. A seta amarela destaca um fragmento de xisto, enquanto a seta branca indica um fragmento de quartzito. (B) Conglomerados clasto-suportados maciços com matriz arenosa, composta por grãos de areia fina a muito grossa, pobremente selecionados. (C) Conglomerados matriz-suportados maciços. A matriz é predominantemente formada por areia média a areia muito grossa. (D) Contatos abruptos (linha tracejada branca) entre os arenitos laminados da associação AF 3 e os conglomerados maciços da associação AF 4. 


\section{DISCUSSÃO}

\subsection{Modelo deposicional}

Baseado nas seções estratigráficas, foi possível observar a distribuição horizontal ao longo de um perfil E-W (aproximadamente $5,5 \mathrm{~km}$ ), e vertical, através de uma sucessão sedimentar de aproximadamente $60 \mathrm{~m}$ de espessura, das associações de fácies descritas (Fig. 2). A distribuição das fácies é caracterizada por uma acentuada transição lateral entre depósitos gravitacionais e eólicos de leste a oeste.

No extremo leste da seção, dominam os espessos depósitos da associação de fácies de fluxo de detritos (AF 4), que se mostram cada vez menos frequentes e espessos em direção ao extremo oeste do perfil (Fig. 2). Nesse sentido, os depósitos de granulação grossa, mal selecionados e maciços são progressivamente substituídos por areias bem selecionadas. As areias texturalmente mais retrabalhadas (grãos arredondados e esféricos) e granulometricamente mais homogêneas compõem as associações AF 1 , AF 2 e AF 3 nas porções intermediárias e mais a oeste do perfil (Fig. 2). A transição nas características superficiais dos grãos denota um crescimento direto do grau de transporte $\mathrm{e}$, consequentemente, o melhor retrabalhamento dos sedimentos para oeste (Goudie et al., 1987; Walker, 1992; Tucker, 2011). Esse trend é acompanhado pela direção média de paleotransporte das dunas eólicas ( 260 azimute), sugerindo que o vento foi o principal agente de reciclagem de sedimentos na sucessão estudada.

Desse modo, entende-se que o extremo leste da seção foi caracterizado por uma zona proximal à antiga área fonte da bacia, onde dominava a deposição por fluxos gravitacionais responsáveis pela sedimentação de camadas espessas e tabulares da associação AF 4 (Figs. 2 e 11). Em contraste, na porção intermediária do perfil, predominava a deposição eólica em um sistema de lençóis de areia. Esse sistema caracterizava-se pela limitada construção de dunas eólicas que, variavelmente, foram afetadas pela incisão de fluxos de detritos e por flutuações do lençol freático (Fig. 11). Por sua vez, no extremo oeste da sucessão, ocorreu o desenvolvimento de campo de dunas eólicas e que representavam as áreas mais secas do sistema. Nessas áreas, as interações dos sistemas eólicos com os fluxos de detritos foram menos frequentes, uma vez que os depósitos da associação AF 4 são pouco espessos e geralmente arranjados em pequenas lentes interestratificadas com esses arenitos eólicos (Fig. 4).

Embora esses ambientes apresentem um maior ou menor predomínio quanto às suas posições espaciais no perfil, as intercalações verticais entre eles são sistemáticas e sugerem sucessivos estágios de expansão e contração dos sistemas deposicionais (Figs. 2 e 11). Esses episódios podem ser atribuídos a dois principais fatores: mudanças periódicas na taxa de subsidência da bacia (Blakey, 1988; Mountney, 1999) e/ou episódios de maior precipitação pluviométrica (Blair, 1994; Mountney, 2006b, Bállico et al., 2017). Ambos os mecanismos podem afetar o posicionamento do lençol freático e o suprimento e/ou disponibilidade de sedimentos para o transporte gravitacional e eólico, modificando as taxas de sedimentação e a distribuição (em área) dos diferentes sistemas deposicionais (Blakey, 1988; Blair, 1994).

A subsidência está diretamente relacionada às reativações das falhas de borda da bacia (Alto da Serra das Encantadas - Fig. 1B), as quais provavelmente controlaram $O$ rejuvenescimento topográfico (altimetria e declividade) das áreas fontes e, consequentemente, a suscetibilidade à ocorrência de fluxos gravitacionais e a carga de sedimentos transportada para o interior da bacia (Keller \& Pinter, 2001; Schumm et al., 2002). Trabalhos anteriores de Paim et al. (2000) e Paim \& Scherer (2007) indicam uma fase de subsidência mecânica acelerada e contínua (sin-rifte) relacionada à deposição do Grupo Guaritas, o que possibilitou a 
frequente deposição por fluxos de detritos nas zonas marginais do rifte.

Já os episódios de maior pluviosidade provavelmente controlaram o balanço hídrico e a intensidade desses fluxos, delimitando assim as áreas de construção eólica nas porções planas da bacia (Clemmensen \& Abrahamsen, 1983; Marconato et al., 2009). Os episódios de maior pluviometria podem ter controlado o maior escoamento superficial de água das áreas fontes até a bacia, proporcionando a elevação do lençol freático e a incisão de pequenos canais fluviais. Essa condição provavelmente também atuou na maior propagação de fluxos gravitacionais em direção ao centro da bacia e na redução da disponibilidade de areia seca para o transporte eólico (Langford \& Chan, 1989, Kocurek, 1991). A formação de pequenas superfícies úmidas nas áreas de lençóis de areia e de interdunas indicam a variabilidade na posição do lençol freático, produzindo alternância entre a sedimentação eólica em condições secas e úmidas.

A ausência de depósitos fluviais evidentes pode ser justificada devido à efemeridade de fluxo desses rios e ao uso de canais fluviais para o escoamento de fluxos de detritos, proporcionando a erosão dos depósitos previamente acumulados e o total preenchimento dos canais por sedimentos aluviais (e.g., Benda, 1990). As geometrias lenticulares das camadas de conglomerados clasto-suportados maciços (Figs. 4 e 7) lembram a geometria, em seção transversal, de pequenos canais fluviais preenchidos (Gibling, 2006; Miall, 2006). Na seção analisada, a associação desses canais com os depósitos da associação de fácies AF 3 indicam a comum incisão fluvial sobre o substrato eólico. Esse processo provavelmente possibilitou o transporte de sedimentos de granulometria maior (seixos e grânulos) para o interior da bacia em períodos de maior umidade (Blair, 1987; Benda, 1990), explicando, assim, a presença de seixos bem retrabalhados no extremo oeste do perfil longitudinal. A continuidade lateral desses paleocanais não foi observada, evidenciando a natureza efêmera da atividade fluvial no sistema (Goudie, 2013). Uma outra hipótese que justificaria a ausência de depósitos fluviais na sucessão estudada é o desenvolvimento de superfícies deflacionárias, por um vento efetivo e subsaturado, nas áreas de lençóis de areia. Nesse contexto, o vento proporcionaria o retrabalhamento e erosão dos depósitos previamente acumulados por descargas fluviais (Langford \& Chan, 1989; Al-Masrahy \& Mountney, 2015)

O acúmulo de lençóis de areia com espessura atípica (até $3 \mathrm{~m}$ de espessura, ver Simplício e Basilici, 2015) indica um suprimento alto de sedimentos, acompanhada por altas taxa de acumulação, mas com disponibilidade limitada de areia seca para a geração de dunas eólicas bem desenvolvidas (Simplício e Basilici, 2015; Bállico et al., 2017). O alto suprimento de sedimento foi uma característica usual em sistemas eólicos prévegetacionais (Eriksson \& Simpson, 1998; Rodríguez-López et al., 2014). No entanto, a restrita construção de dunas em áreas de lençóis de areia poderia estar associada a (i) inundações periódicas, (ii) população significativa de sedimentos de granulação grossa, (iii) elevação do nível freático, (iv) presença de superfícies de adesão e/ou (v) ação da cobertura vegetal (Kocurek \& Nielson, 1986, Dal'Bó \& Basilici, 2015). As três primeiras hipóteses são as mais prováveis para justificar o desenvolvimento do sistema de lençol de areia estudado, em função da: (i) frequente presença de seixos e a bimodalidade dos grãos de areia nos depósitos e do (ii) desenvolvimento de superfícies úmidas. Esse último fator auxiliaria na maior retenção de sedimentos no substrato eólico, proporcionando o desenvolvimento de altas taxas de acumulação de areia e, a longo prazo, a formação de espessos depósitos de lençóis de areia (Biswas, 2005; Basilici et al., 2020).

Os campos de dunas eólicas provavelmente se concentravam nas porções mais distais em 
relação às áreas fontes, onde as superfícies deposicionais foram majoritariamente secas. A construção de dunas eólicas nessas áreas pode ter sido controlada por dois motivos. $\mathrm{O}$ primeiro é a diminuição da capacidade do vento em relação ao aporte sedimentar, proporcionando a saturação do fluxo de ar, a acessão vertical do substrato seco e, consequentemente, o desenvolvimento de campo de dunas (Mountney, 2006b, Mesquita et al., 2021). A segunda hipótese é a variações de umidade no sistema a partir do balanço hídrico negativo e/ou do nível freático mais profundo (Fig. 11) (Mountney \& Thompson, 2002; Mountney \& Jagger, 2004). Apesar dos depósitos de campo de dunas eólicas indicarem condições secas de deposição, o desenvolvimento de pequenas superfícies de adesão nas áreas de interdunas sugerem estágios com o nível do lençol freático alto durante a sedimentação (Mountney \& Thompson, 2002).

A distribuição horizontal de lençóis de areia e dunas eólicas pode ter sido controlada por gradientes de proximidade com as áreas fontes e pela posição do lençol freático (Fig. 11). A sobreposição frequente e de maneira cíclica dos depósitos das associações de fácies AF 3 e AF 4 indica que os sistemas aluviais contribuíram significativamente para o suprimento de sedimentos da bacia, subsequentemente retrabalhados pelo vento e disponíveis para a construção eólica. Entretanto, a atuação de fluxos gravitacionais na margem do rifte somente possibilitou o desenvolvimento de campos de dunas nas porções mais internas da bacia (Fig. 11). Oscilações do lençol freático provavelmente atuaram na distribuição de umidade no sistema, proporcionaram a expansão e contração dos sistemas eólicos. Em períodos de lençol freático baixo, os ambientes eólicos expandiam-se em função: (i) da constante ação do vento na seleção de grão e no retrabalhamento de depósitos não-eólicos e (ii) da maior disponibilidade de areia seca (na área fonte) para a construção de dunas (Fig. 11). Exemplos similares desse processo são reportados em ambientes áridos e semiáridos modernos (e.g., Veiga \& Spalletti, 2007; AlMasrahy \& Mountney, 2015).

As variações topográficas do sistema e a subsidência tectônica da bacia possivelmente tenham influenciado no posicionamento do lençol freático durante a sedimentação eólica. Em bacias com altas taxas de subsidência, o nível do lençol freático pode se manter elevado em função do rebaixamento das superfícies deposicionais (Blakey, 1988, Mountney et al., 1999). Essa relação parece ser aplicável para sucessão estudada, a julgar pelas altas taxas de subsidência mecânica descritas por Paim et al. (2000) para o estágio de sedimentação do Grupo Guaritas (Bacia do Camaquã). Por outro lado, as variações topográficas podem controlar a interação entre a superfície deposicional eólica e o nível freático. Nas partes mais altas do sistema, o nível freático raramente excederia a superfície deposicional e as dunas eólicas se desenvolveriam mais facilmente. Entretanto, nas partes mais baixas do sistema, o lençol freático permaneceria raso, produzindo a captura de sedimentos nas superfícies deposicionais úmidas e o desenvolvimento de lençóis de areia (Mountney \& Russell, 2009; Basilici et al., 2021). Ou seja, o zoneamento das superfícies deposicionais seca e úmida no sistema poderia ocorrer mesmo sem a interferência da atividade pluviométrica ou por mudanças climáticas. 

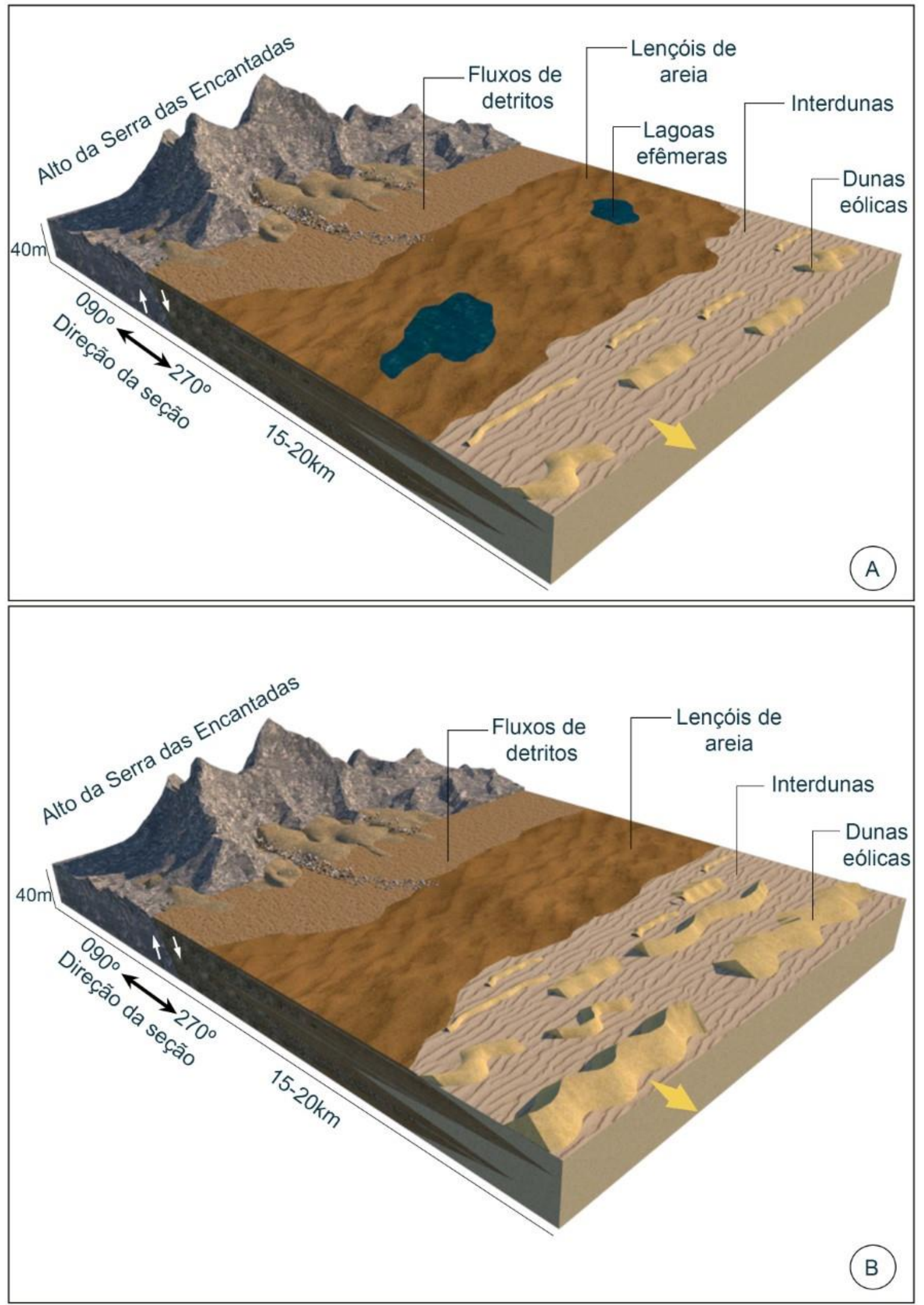

Figura 11. Modelo paleodeposicional e paleoambiental para a sucessão estudada. (A) Período de maior umidade representado pela expansão das áreas dominadas por fluxos de detritos e por lençóis de areia. A ação de um lençol freático raso originou a formação de pequenas lagoas efêmeras e a restrição do campo de dunas em áreas mais internas da bacia. (B) Período de menor umidade dos sistemas e que proporcionou a expansão do campo de dunas e a contração dos outros ambientes deposicionais. A seta laranja indica a direção de paleotransporte das dunas. 


\subsection{Dinâmica deposicional em um contexto pré-vegetação}

Embora a vegetação não tenha sido considerada, dado a idade da sucessão estudada (Cambriano Inferior), a sua ausência foi um fator essencial na geração e transporte dos sedimentos eólicos. A inexistência de cobertura vegetal provavelmente aumentava: (i) a instabilidade dos declives da área fonte e (ii) a exposição de rochas à ação de agentes erosivos, facilitando a geração e o escoamento superficial de sedimentos para a bacia. Sob uma ação efetiva do vento, essa condição proporcionou uma maior quantidade de sedimentos disponíveis ao transporte eólico e, consequentemente, a formação de campo de dunas e/ou lençóis de areia (Eriksson \& Simpson, 1998, RodríguezLópez et al., 2014). Basilici et al. (2021) propõem que essa configuração incentivou um desenvolvimento generalizado de sistemas eólicos nas superfícies continentais pré-devonianas, inclusive em ambientes úmidos. Entretanto, a ausência de agente de fixação de areia (e.g., vegetação) não proporcionou a acumulação e consequente preservação de espessos depósitos eólicos, exceto quando vinculados a um lençol freático ascendente ou a alta taxa de subsidência da bacia (Basilici et al., 2020;
Mesquita et al., 2021; Basilici et al., 2021). Esses fatores, associados ao soterramento dos depósitos eólicos por fluxos gravitacionais, provavelmente atuaram no processo de acumulação e preservação da sucessão estudada.

A coexistência lateral entre fluxos gravitacionais e eólicos em sistemas modernos requerem superfícies deposicionais de grande escala (escala de erg) (cf., Porter, 1986; Al-Masrahy \& Mountney, 2015). Entretanto, variações significativas no ambiente deposicional ocorreram em poucos quilômetros na sucessão estudada. Diante das condições sedimentares da Terra prévegetação (alto suprimento de areia), sistemas eólicos provavelmente foram facilmente desenvolvidos em variados contextos paleoambientais, principalmente em função da ininterrupta deflação eólica sobre um substrato continental "nu". Logo, sistemas eólicos antigos possivelmente não requeriam grandes superfícies deposicionais para o seu desenvolvimento e acumulação, mesmo em contextos de maior umidade e variavelmente afetados por fluxos graviatcionais, tal como observado em seus correlatos modernos (Porter, 1986; Pye \&Tsoar, 2009; Al-Masrahy \& Mountney, 2015). 


\section{CONCLUSÕES}

A partir da análise faciológica dos depósitos presentes no intervalo estudado entre as Formações Pedra das Torrinhas e Pedra Pintada, é possível fazer as seguintes considerações:

- O ambiente deposicional era caracterizado pela coexistência lateral entre os fluxos gravitacionais e a deposição eólica, distribuídos em função de gradientes de umidade e da proximidade com a área fonte. Esses sistemas provavelmente sofreram expansão e contração ao longo de sua atividade a partir de possíveis atividades tectônicas e/ou períodos de maior pluviometria.

- A construção de dunas eólicas pode ter sido controlada por: (i) diminuição da capacidade do vento em relação ao aporte sedimentar e (ii) variações de umidade no sistema. As variações de umidade possivelmente estiveram associadas ao posicionamento do nível freático em relação as superfícies deposicionais, limitando, espacialmente, as taxas e as áreas de construção de dunas eólicas ao longo do tempo. Duas hipóteses podem explicar as oscilações do nível freático no sistema: (i) episódios de maio ou menor pluviometria e (ii) diferenças topográficas da superfície deposicional e/ou subsidência tectônica.

- A ação do vento efetivo pode ter produzido uma ininterrupta seleção e reciclagem de depósitos aluviais, alimentando os sistemas eólicos em direção a oeste da bacia.

- A ausência de vegetação possibilitou o maior desenvolvimento de fluxos gravitacionais, em função da maior exposição de rochas ao intemperismo e erosão e o alto aporte de sedimentos para a construção eólica. A efetiva ação do vento e o elevado suprimento sedimentar possivelmente proporcionou o desenvolvimento contemporâneo de sistemas eólicos e não eólicos (fluxo de detritos) em pequena escala, situação incomum em correlatos modernos.
- $\quad$ O modelo paleoambiental proposto apresenta uma relação frequente entre ambientes de campo de dunas e de lençóis de areia. Essa interação não foi previamente identificada por trabalhos relacionados a Formação Pedra Pintada, provavelmente por se concentrar nas porções transicionais do sistema eólico representado por essa unidade.

\section{AGRADECIMENTOS}

Os autores agradecem ao Conselho Nacional de Desenvolvimento Científico e Tecnológico (CNPq) pelo suporte financeiro para o desenvolvimento desta pesquisa concedido a Dra. Juliana Pertille da Silva através do Edital Universal-2018, processo $n^{\circ}$ 436073/2018-8. Os autores também agradecem a Agência Nacional de Petróleo, Gás Natural e Biocombustíveis (ANP) pela concessão da bolsa de pesquisa ao Dr. Áquila Ferreira Mesquita, processo no 042919/2021, e ao revisor anônimo pelos valiosos comentários que proporcionaram a melhora do manuscrito original.

\section{REFERÊNCIAS BIBLIOGRÁFICAS}

ABRANTES JR. F.R., BASILICI G., SOARES M.V.T. 2020. Mesoproterozoic erg and sand sheet system: Architecture and controlling factors (Galho do Miguel Formation, SE Brazil). Precambrian Research: 338, 105592.

AHLBRANDT T.S., FRYBERGER S.G. 1981. Sedimentary features and significance of interdune deposits. SEPM Special Publications: 31, 293-314.

ALLEN, J.R.L. 1979. A model for the interpretation of wave ripple-marks using their wavelength, textural composition, and shape. Journal of Geological Society of London: 136, 673-682.

AL-MASRAHY M.A., MOUNTNEY N.P. 2013. Remote sensing of spatial variability in aeolian dune and interdune morphology in the Rub' Al-Khali, Saudi Arabia. Aeolian Research: 11, 
155-170.

AL-MASRAHY M.A., MOUNTNEY N.P. 2015. A classification scheme for fluvial-aeolian system interaction in desert-margin settings. Aeolian Research, 17, 67-88.

ALMEIDA R. P. 2005. Tectônica e sedimentação do Ediacarano ao Ordoviciano: exemplos do Supergrupo Camaquã (RS) e do Grupo Caacupé (Paraguai oriental). Tese de Doutorado. Programa de Pós-Graduação em Geociências, Instituto de Geociências, Universidade de São Paulo, 203p.

ALMEIDA D.D.P.M.D., LOPES R.D.C., GOMES C.H. 2000. Petrography and geochemistry of the volcanic rocks of the Rodeio Velho Member, ordovician of the Camaquã basin (RS-Brazil): preliminary results. Revista Brasileira de Geociências: 30, 763-768

ALMEIDA R.P., JANIKIAN L., FRAGOSO-CESAR A.R.S., MARCONATO A. 2009. Evolution of a rift basin dominated by subaerial deposits: The Guaritas Rift, Early Cambrian, Southern Brazil. Sedimentary Geology: 217, 30-51.

ALMEIDA R.P., JANIKIAN L., FRAGOSO-CESAR A.R.S., FAMBRINI G.L. 2010. The Ediacaran to Cambrian Rift System of Southeastern South America: Tectonic Implications. The Journal of Geology: 118, 145-161.

ALMEIDA R.P., SANTOS M.G.M., FRAGOSOCESAR A.R.S., JANIKIAN L., FAMBRINI G.L., 2012. Recurring extensional and strike-slip tectonics after the Neoproterozoic collisional events in the southern Mantiqueira province. Anais da Academia Brasileira de Ciências: 84, 347-376.

ANDERTON R. 1985. Clastic facies models and facies analysis. Geological Society of London Special Publications: 18, 31-47.

BAGNOLD R.A. 1946. Motion of waves in shallow water. Interaction between waves and sand bottoms. Proceedings of the Royal Society of London - Series A - Mathematical and Physical Sciences: 187, 1-18.

BÁLLICO M.B., SCHERER C.M.S., MOUNTNEY N.P., SOUZA E.G., REIS A.D., RAJA GABAGLIA G.P., MAGALHÃES A.J.C. 2017. Sedimentary cycles in a Mesoproterozoic aeolian ergmargin succession: Mangabeira Formation, Espinhaço Supergroup, Brazil. Sedimentary Geology: 349, 1-14.

BASILICI G., DAL'BÓ P.F.F. 2014. Influence of subaqueous processes on the construction and accumulation of an aeolian sand sheet. Earth Surface Processes and Landforms: 39, 1014-1029.

BASILICI G., SOARES M.V.T., MOUNTNEY N.P., COLOMBERA L. 2020. Microbial influence on the accumulation of Precambrian aeolian deposits (Neoproterozoic, Venkatpur Sandstone Formation, Southern India). Precambrian Research: 347, 105854.

BASILICI G., MESQUITA Á.F., SOARES M.V.T., JANOSKO J., MOUNTNEY N., COLOMBERA L. 2021. A Mesoproterozoic hybrid dry-wet aeolian system: Galho do Miguel Formation, SE Brazil. Precambrian Research: 359, 106216.

BATEZELLI A.; BASILICI G. 2016. Arquitetura e mecanismos deposicionais em sistemas aluviais holocênicos de clima árido no oeste argentino e comparação com depósitos neocretáceos brasileiros. Revista Brasileira de Geociências: 37, 821-840.

BENDA L. 1990. The influence of debris flows on channels and valley floors in the Oregon Coast Range, USA. Earth Surface Processes and Landforms: 15, 457-466.

BICCA M.M., CHEMALE JR F., JELINEK A.R., DE OLIVEIRA C.H.E., GUADAGNIN F., ARMSTRONG R. 2013. Tectonic evolution and provenance of the Santa Bárbara Group, Camaquã Mines region, Rio Grande do Sul, Brazil. Journal of South American Earth Sciences: 48, 173-192.

BISWAS A. 2005. Coarse aeolianites: sand sheets and zibar-interzibar facies from the Mesoproterozoic Cuddapah Basin, India. Sedimentary Geology: 174, 149-160.

BLAIR T.C. 1987. Tectonic and hydrologic controls on cyclic alluvial fan, fluvial, and lacustrine rift-basin sedimentation, JurassicLowermost Cretaceous Todos Santos 
Formation, Chiapas, Mexico. Journal of Sedimentary Research: 57, 845-862.

BLAIR T.C. 2001. Outburst flood sedimentation on the proglacial Tuttle Canyon alluvial fan, Owens Valley, California, USA. Journal of Sedimentary Research: 71, 657-679.

BLAIR T.C., MCPHERSON J.G. 1998. Recent debris-flow processes and resultant form and facies of the Dolomite alluvial fan, Owens Valley, California. Journal of Sedimentary Research: 68, 800-818.

BLAIR T.C., MCPHERSON J.G. 1994. Alluvial fan processes and forms. In: PARSON J.A., ABRAHAMS A.D. (eds) Geomorphology of desert environments. Springer, Dordrecht, 354-4020.

BLAIR T.C., MCPHERSON J.G. 2009. Processes and forms of alluvial fans. In: PARSON J.A., ABRAHAMS A.D. (eds) Geomorphology of desert environments. Springer, Dordrecht, 413-467p.

BLAKEY R.C. 1988. Basin tectonics and erg response. Sedimentary Geology: 56, 127-151.

BORBA A.W., MIZUSAKI A.M.P., SANTOS J.O.S., MCNAUGHTON N.J., ONOE A.T., HARTMANN L.A. 2008. U-Pb zircon and 40Ar$39 A r$ K-feldspar dating of syn-sedimentary volcanism of the Neoproterozoic Maricá Formation: constraining the age of foreland basin inception and inversion in the Camaquã Basin of southern Brazil. Basin Research: 20, 359-375.

BOSE P.K., ERIKSSON P.G., SARKAR S., WRIGHT D.T., SAMANTA P., MUKHOPADHYAY S., MANDAL S., BANERJEE S., ALTERMANN W. 2012. Sedimentation patterns during the Precambrian: A unique record? Marine and Petroleum Geology: 33, 34-68.

BROOKFIELD M.E. 1977. The origin of bounding surfaces in ancient aeolian sandstones. Sedimentology: 24, 303-332.

CALHOUN N.C., CLAGUE J.J. 2018. Distinguishing between debris flows and hyperconcentrated flows: an example from the eastern Swiss Alps. Earth Surface
Processes and Landforms: 43, 1280-1294.

CLEMMENSEN, L.B. 1988. Aeolian morphology preserved by lava cover, the Precambrian Mussartut member, Eriksfjord Formation, South Greenland. Bulletin of the Geological Society of Denmark: 37, 105-116.

CLEMMENSEN L.B., ABRAHAMSEN K. 1983. Aeolian stratification and facies association in desert sediments, Arran basin (Permian), Scotland. Sedimentology: 30, 311-339.

CLEMMENSEN L.B., DAM, G. 1993. Aeolian sand-sheet deposits in the Lower Cambrian Neks $\varnothing$ Sandstone Formation, Bornholm, Denmark: sedimentary architecture and genesis. Sedimentary Geology: 83, 71-85.

COLLINSON J., MOUNTNEY N.P., 2019. Sedimentary Structures. Dunedin Academic Press, London, 352p.

CPRM - SERVIÇO GEOLÓGICO DO BRASIL 2008. Mapa Geológico do Estado do Rio Grande do Sul. Porto Alegre, Mapa Geológico, Escala: 1:750.000.

DAL'BÓ P.F.F., BASILICI, G. 2015. Intermontane eolian sand sheet development, Upper Tulum Valley, centralwestern Argentina. Brazilian Journal of Geology: 45, 97-115.

DE HAAS T., VENTRA D., CARBONNEAU P. E., KLEINHANS M. G. Debris-flow dominance of alluvial fans masked by runoff reworking and weathering. Geomorphology: 217, 165-181.

DEYNOUX M., KOCUREK G., PROUST J. N. 1989. Late Proterozoic periglacial aeolian deposits on the west African platform, Taoudeni Basin, western Mali. Sedimentology: 36, 531-549.

ERIKSSON K.A., SIMPSON E.L. 1998. Controls on spatial and temporal distribution of Precambrian eolianites. Sedimentary Geology: 120, 275-294.

ERIKSSON P.G., CATUNEANU O., SARKAR S., TIRSGAARD H. 2005. Patterns of sedimentation in the Precambrian. Sedimentary Geology: 176, 17-42.

FRAGOSO-CESAR A.R.S., FAMBRINI G.L., 
ALMEIDA R.P., PELOSI A.P.M.R., JANIKIAN L., RICCOMINI, C., MACHADO R., NOGUEIRA A.C.R., SAES G.S. 2000. The Camaquã extensional basin: Neoproterozoic to early Cambrian sequences in southernmost Brazil. Brazilian Journal of Geology: 30, 439441.

FRYBERGER S.G., AHLBRANDT T.S., ANDREWS S. 1979. Origin, sedimentary features, and significance of low angle eolian sand sheet deposits, Great Sand Dunes National Monument and vicinity, Colorado. Journal of Sedimentary Research: 49, 733-746.

FRYBERGER S.G., HESP P., HASTINGS, K. 1992. Aeolian granule ripple deposits, Namibia. Sedimentology: 39, 319-331.

GIBLING M.R. 2006. Width and thickness of fluvial channel bodies and valley fills in the geological record: a literature compilation and classification. Journal of sedimentary Research: 76, 731-770.

GLENNIE, K.W. 1987. Desert sedimentary environments, present and past - A summary. Sedimentary Geology: 50, 135-165.

GODINHO L.P.S., ALMEIDA R.P., SANTOS M.G.M., MARCONATO A., FRAGOSO-CESAR A.R.S. 2013. Fácies sedimentares e elementos arquitetônicos das Formações Serra do Apertado e Pedra Pintada na Região das Minas do Camaquã - RS. Geologia USP - Série Científica: 13, 22-48.

GOUDIE A.S. 2013. Arid and semi-arid geomorphology. Cambridge university press, Cambridge, 461p.

GOUDIE A.S., WARREN A., JONES D.K.C., COOKE R.U. 1987. The character and possible origins of the aeolian sediments of the Wahiba Sand Sea, Oman. Geographical Journal: 153, 231-256.

HARTMANN L., NARDI L., FORMOSO M., REMUS M., DE LIMA E., MEXIAS A. 1999. Magmatism and metallogeny in the crustal evolution of Rio Grande do Sul Shield, Brazil. Pesquisas em Geociências: 26, 45-63.

HOOKE R.L. 1987. Mass movement in semiarid environments and the morphology of alluvial fans. In: FOOKES P.G., LEE E.M., GRIFFITHS J.S. (eds.) Engineering Geomorphology: Theory and Practice. John Wiley and Sons New York, New York, 312p.

HUNTER, R.E. 1977. Basic types of stratification in small eolian dunes. Sedimentology: 24, 361-387.

JANIKIAN L., ALMEIDA R.P., DA TRINDADE R.I.F., FRAGOSO-CESAR A.R.S., D'AGRELLAFILHO M.S., DANTAS E.L., TOHVER E. 2008. The continental record of Ediacaran volcanosedimentary successions in southern Brazil and their global implications. Terra Nova: 20, 259-266.

KELLER E.A., PINTER N. 2001. Active tectonics: Earthquakes, Uplift and Landscape. Person, New Jersey, 384p.

KOCUREK G. 1988. First-order and super bounding surfaces in eolian sequencesbounding surfaces revisited. Sedimentary Geology: 56, 193-206.

KOCUREK G. 1991. Interpretation of ancient eolian sand dunes. Annual Review of Earth and Planetary Sciences: 19, 43-75.

KOCUREK G., DOTT, R.H. 1981. Distinctions and uses of stratification types in the interpretation of eolian sand. Journal of Sedimentary Research: 51, 579-595.

KOCUREK G., NIELSON J. 1986. Conditions favourable for the formation of warm-climate aeolian sand sheets. Sedimentology: 33, 795816.

KOCUREK G., LANCASTER N. 1999. Aeolian system sediment state: theory and Mojave Desert Kelso dune field example. Sedimentology: 46, 505-515.

KOCUREK G, DAY M. 2018. What is preserved in the aeolian rock record? A Jurassic Entrada Sandstone case study at the Utah-Arizona border. Sedimentology: 65, 13011321.HAVHOLM K.G., KOCUREK G. 1994. Factors controlling aeolian sequence stratigraphy: clues from super bounding surface features in the Middle Jurassic Page Sandstone. Sedimentology: 41, 913934.JONES F.H., SCHERER C.M.S., KUCHLE J. 
2016. Facies architecture and stratigraphic evolution of aeolian dune and interdune deposits, Permian Caldeirão Member (Santa Brígida Formation), Brazil. Sedimentary Geology: 337, 133-150.

LANCASTER N. 1982. Dunes on the Skeleton Coast, Namibia (South West Africa): geomorphology and grain size relationships. Earth Surface Processes and Landforms: 7, 575-587.

LANGFORD R.P., CHAN, M.A. 1989. Fluvial-aeolian interactions: Part II, ancient systems. Sedimentology: 36, 1037-1051.

LEBEAU L.E., IELPI, A. 2017. Fluvial channelbelts, floodbasins, and aeolian ergs in the Precambrian Meall Dearg Formation (Torridonian of Scotland): Inferring climate regimes from pre-vegetation clastic rock records. Sedimentary Geology: 357, 53-71.

MARCONATO A., ALMEIDA R.P., SANTOS M.G.M., NÓBREGA J.E.S., SOUZA R.B. 2009. Alluvial-eolian interaction in a Cambrian rift margin: the Pedra das Torrinhas and Pedra Pintada formations (Guaritas Group, RS). Anais da Academia Brasileira de Ciências: 81, 819-836.

MESQUITA Á.F., BASILICI G., SOARES M.V.T., GARCIA R.G.V. 2021. Morphology, accumulation and preservation of draa systems in a Precambrian erg (Galho do Miguel Formation, SE Brazil). Sedimentary Geology: 412, 105807.

MIALL A.D. 2006. Reconstructing the architecture and sequence stratigraphy of the preserved fluvial record as a tool for reservoir development: A reality check. AAPG Bulletin: 90, 989-1002.

MOUNTNEY N. 2006a. Eolian Facies Models. In: POSAMENTIER H.W., WALKER R.G. (Eds.) Facies Models Revisited. SEPM (Society for Sedimentary Geology), Tulsa, pp. 19-83.

MOUNTNEY N. 2006b. Periodic accumulation and destruction of aeolian erg sequences in the Permian Cedar Mesa Sandstone, White Canyon, southern Utah, USA. Sedimentology: 53, 789-823.
MOUNTNEY N.P. 2012. A stratigraphic model to account for complexity in aeolian dune and interdune successions. Sedimentology: 59, 964-989.

MOUNTNEY N.P., THOMPSON, D.B. 2002. Stratigraphic evolution and preservation of aeolian dune and damp/wet interdune strata: an example from the Triassic Helsby Sandstone Formation, Cheshire Basin, UK. Sedimentology: 49, 805-833.

MOUNTNEY N.P., JAGGER, A. 2004. Stratigraphic evolution of an aeolian erg margin system: the Permian Cedar Mesa Sandstone, SE Utah, USA. Sedimentology: 51, 713-743.

MOUNTNEY N.P., RUSSELL A.J. 2009. Aeolian dune-field development in a water table-controlled system: Skeiđarársandur, Southern Iceland. Sedimentology: 56, 21072131.

MOUNTNEY N., HOWELL J., FLINT S., JERRAM D. 1999. Climate, sediment supply and tectonics as controls on the deposition and preservation of the aeolian-fluvial Etjo Sandstone Formation, Namibia. Journal of the Geological Society: 156, 771-777.

MULDER T., ALEXANDER J. 2001. The physical character of subaqueous sedimentary density flows and their deposits. Sedimentology: 48, 269-299.

NEMEC W., STEEL R.J. 1984. Alluvial and coastal conglomerates: their significant features and some comments on gravelly mass-flow deposits. AAPG Bulletin: 10, 1-31.

NICHOLS, G. 2009. Sedimentology and Stratigraphy. Wiley-Blackwell, 432p.

NIELSON J., KOCUREK G. 1986. Climbing zibars of the Algodones. Sedimentary Geology: 48, 1-15.

PAIM P.S.G., SCHERER, C.M.S. 2003. Arquitetura estratigráfica de sucessões flúvioeólica: o exemplo do Alogrupo Guaritas na região de Pedra Pintada, Rio Grande do Sul, Brasil. In: PAIM P.S.G., FACCINI U.F., NETTO, R.G. (eds.) Geometria, arquitetura e heterogeneidades de corpos sedimentares: 
estudo de casos. Universidade do Vale do Rio dos Sinos, São Leopoldo, 38-58p.

PAIM P.S.G., SCHERER, C.M.S. 2007. Highresolution stratigraphy and depositional model of wind-and water-laid deposits in the ordovician Guaritas rift (Southernmost Brazil). Sedimentary Geology: 202, 776-795.

PAIM P.S.G., CHEMALE JR F., LOPES R.C. 2000. A Bacia do Camaquã. In: HOLZ M., DE ROSS, L.F. (eds) Geologia do Rio Grande do Sul. Universidade Federal do Rio Grande do Sul, Porto Alegre, 231-274.

PAIM P.S.G., CHEMALE JR F., WILDNER W. 2014. Estágio evolutivos da Bacia do Camaquã (RS). Ciência e Natura: 36, 183-193.

PORTER M.L. 1986. Sedimentary record of erg migration. Geology: 14, 497.

PULVERTAFT T.C.R. Aeolian dune and wet interdune sedimentation in the middle Proterozoic Dala Sandstone, Sweden. Sedimentary geology: 44, 93-111.

RODRÍGUEZ-LÓPEZ J.P., CLEMMENSEN L.B., LANCASTER N., MOUNTNEY N.P., VEIGA G.D. 2014. Archean to Recent aeolian sand systems and their sedimentary record: Current understanding and future prospects. Sedimentology: 61, 1487-1534.

ROSS G.M. 1983. Proterozoic aeolian quartz arenites from the Hornby Bay Group, Northwest Territories, Canada: Implications for Precambrian aeolian processes. Precambrian Research: 20, 149-160.

RUBIN D.M., CARTER C.L. 2006. Crossbedding, bedforms and paleocurrents. SEMP Society for Sedimentary Geology, Tulsa, 187p.

SCHERER C.M.S. 2000. Eolian dunes of the Botucatu Formation (Cretaceous) in southernmost Brazil: morphology and origin. Sedimentary Geology: 137, 63-84.

SCHUMM S.A., SCHUMM S.A., DUMONT J.F., HOLBROOK J.M. 2002. Active tectonics and alluvial rivers. Cambridge University Press, Cambridge, 292p.

SIMPLICIO F., BASILICI G. 2015. Unusual thick eolian sand sheet sedimentary succession:
Paleoproterozoic Bandeirinha Formation, Minas Gerais. Brazilian Journal of Geology: 45, 3-11.

TROMBETTA M.C., GUADAGNIN F., KUMAIRA S., CARON F., GONÇALVES Í.G. 2019. Composition and diagenesis of Neoproterozoic Guaritas Group sandstones in the Minas do Camaquã fault zone, Camaquã Basin. Journal of South American Earth Sciences: 90, 1-11.

TSOAR, H., PYE, K. 2009. Aeolian sand and sand dunes. Springer Berlin Heidelberg, Berlin, 474p.

TUCKER M.E. 2011. Sedimentary rocks in the field: a practical guide. John Wiley \& Sons, London, 288p.

VEIGA G.D., SPALLETTI L.A. 2007. The Upper Jurassic (Kimmeridgian) fluvial-aeolian systems of the southern Neuquén Basin, Argentina. Gondwana Research: 11, 286-302.

Submetido em 29/05/2021 Aceito em 15/07/2021 